\title{
Performance Management of Supply Chain Sustainability in Small and Medium-Sized Enterprises Using a Combined Structural Equation Modelling and Data Envelopment Analysis
}

\section{Prasanta Kumar Dey, et al. [full author details at the end of the article]}

Accepted: 6 November 2019 / Published online: 18 November 2019

(c) The Author(s) 2019

\begin{abstract}
Although the contribution of small and medium-sized enterprises (SMEs) to economic growth is beyond doubt, they collectively affect the environment and society negatively. As SMEs have to perform in a very competitive environment, they often find it difficult to achieve their environmental and social targets. Therefore, making SMEs sustainable is one of the most daunting tasks for both policy makers and SME owners/managers alike. Prior research argues that through measuring SMEs' supply chain sustainability performance and deriving means of improvement one can make SMEs' business more viable, not only from an economic perspective, but also from the environmental and social point of view. Prior studies apply data envelopment analysis (DEA) for measuring the performance of groups of SMEs using multiple criteria (inputs and outputs) by segregating efficient and inefficient SMEs and suggesting improvement measures for each inefficient SME through benchmarking it against the most successful one. However, DEA is limited to recommending means of improvement solely for inefficient SMEs. To bridge this gap, the use of structural equation modelling (SEM) enables developing relationships between the criteria and sub-criteria for sustainability performance measurement that facilitates to identify improvement measures for every SME within a region through a statistical modelling approach. As SEM suggests improvements not from the perspective of individual SMEs but for the totality of SMEs involved, this tool is more suitable for policy makers than for individual company owners/managers. However, a performance measurement heuristic that combines DEA and SEM could make use of the best of each technique, and thereby could be the most appropriate tool for both policy makers and individual SME owners/managers. Additionally, SEM results can be utilized by DEA as inputs and outputs for more effective and robust results since the latter are based on more objective measurements. Although DEA and SEM have been applied separately to study the sustainability of organisations, according to the authors' knowledge, there is no published research that has combined both the methods for sustainable supply chain performance measurement. The framework proposed in the present study has been applied in two different geographical locations-Normandy in France and Midlands in the UK-to demonstrate the
\end{abstract}


effectiveness of sustainable supply chain performance measurement using the combined DEA and SEM approach. Additionally, the state of the companies' sustainability in both regions is revealed with a number of comparative analyses.

Keywords Sustainability $\cdot$ Supply chain $\cdot$ SMEs $\cdot$ DEA $\cdot$ SEM $\cdot$ Benchmarking · Performance measurement

\section{Introduction}

Climate change presents one of the most serious environmental challenges faced by humanity today (Dey et al. 2018). The achievement of sustainability is a major issue for organizations worldwide. Enterprises need to both maintain and improve their market position and fulfill their environmental and social responsibilities (Halkos and Evangelinos 2002). There is a growing literature analyzing the interactions between economy, society and the environment. The focus of most studies up to date, however, has been on the activities of large-scale companies, while less is known about the operations of small and medium-sized enterprises (SMEs) (Johnson and Schaltegger 2016), which the majority of published studies on sustainability have largely ignored. SMEs make significant contributions to the global economy; hence governments increasingly promote the development of these enterprises in recognition of the critical role they play in the socio-economy (Vidal 2013). While SMEs are of crucial importance in the economic growth across the world, they also impose collectively considerable pressures on the environment (Mollenkopf 2008; Johnson and Schaltegger 2016).

In comparison with large companies, small and medium-sized enterprises tend to be less engaged in sustainability management practices, thus limiting their potential for reducing environmental and social impacts. SMEs are much less likely to have sustainability goals and practices in place (Johnson 2015) and are potentially more ill-prepared than their larger counterparts to cope with sustainability challenges. This is due to limited financial and managerial resources, lack of time and shortage of (staff) skills in sustainability-related practices (Sullivan-Taylor and Branicki 2011). SMEs tend to plan in the short term, simply reacting to arising situations, and focusing on their very survival. Likewise, they share less formalized structures and codified policies while they are most usually owner-managed resulting in a command and control management culture (e.g. Ates et al. 2013). Other reasons for their inefficiency include the lack of internal capacity (e.g. financial resources, human resources, technologies, business processes and R\&D activities), weak supporting frameworks and, in many cases, political indulgence by policy makers (see Zhu and Sarkis 2004; Dey and Cheffi 2012).

The theoretical and practical underpinning of this study relates to the sustainability performance (Seuring and Muller 2008) of SMEs. Our aim is to develop a performance measurement (PM) method of supply chain sustainability and a management framework for SMEs through revealing the characteristics, issues and challenges of sustainable supply chain management, with a view to enhancing the 
sustainability performance of SMEs. Although previous research explores various sustainability PM models (see, e.g., Büyüközkan and Karabulut 2018; Acquaye et al. 2017), supply chain sustainability measurements for SMEs are scant. Up till now there has not been a thorough research project on the impact of implementing sustainable supply chain management practices on the performance of SMEs. Available models either analyze the sustainability performance of SMEs using multiple criteria and objectively distinguish between efficient and inefficient companies or identify causal relationships among criteria so as to objectively come up with overall improvement measures. More specifically, one methodological approach in prior research applies Data Envelopment Analysis (DEA) for measuring the performance of a group of SMEs using multiple criteria (inputs and outputs), segregating in this way inefficient SMEs from efficient ones and suggesting improvement initiatives for each inefficient company through benchmarking it against the most successful one. However, this approach is limited to suggesting means of improvement solely for the individual inefficient SMEs under study. To mend this gap, another methodological approach employs Structural Equation Modelling (SEM) which enables the development of more general relationships between the criteria and sub-criteria for sustainability performance measurements and helps identify improvement measures for every SME within a region through a statistical modelling technique based on selected sampling of SMEs (Malesios et al. 2018). As SEM suggests improvements in criteria level not from the point of view of an individual SME, this tool can be considered as more suitable for policy makers compared to individual SME owners/ managers. However, a performance measurement heuristic that combines both DEA and SEM could make use of the best of each technique, and thereby could be the most appropriate tool for both policy makers and individual SME owners/managers.

Typically, for studies measuring sustainability performance it can be assumed that the importance of the sustainability criteria and sub-criteria is equal, e.g. through the simple aggregation of individual SME sustainability performance scores in each one of sustainability criteria. Our modelling approach offers the accommodation of criteria weights. Among the advantages of a combined SEM and DEA analysis is the ability to obtain through SEM more suitable input and output latent constructs of sustainability practices and performances, instead of utilizing average and aggregate scores from individual observed items (see, e.g. Thanassoulis et al. 2017). We believe that the combined approach is more robust since it essentially comprises a suitably adjusted index of practices/performances that is weighted according to the magnitude of the effect each individual observed item depicts on the corresponding latent construct of sustainability. However, according to the authors' knowledge, there is no research available that combines the above two aspects within the same analysis framework in order to take advantage of the best of the two approaches. In view of the above, the objective of this study is to develop a framework to measure the supply chain sustainability of SMEs using a combined DEA and SEM approach. SEM is employed for measuring the sustainability performance of a group of SMEs using combined data, whereas DEA utilizes the individual SME sustainability performance scores rankings produced by SEM and segregates between efficient and inefficient SMEs. The proposed framework has been applied to a carefully selected sample of SMEs in two geographic locations-viz. Normandy of France and 
Midlands of the UK - in order to not only validate the framework but also reveal the characteristics of sustainable supply chains of SMEs in both regions. The grouping was performed so as to ensure high degree of validity by comparing the manufacturing enterprises in two developed nations, namely UK and France. The regions where the SMEs are based in each country are industrial areas. The two developed countries have similar supply chain management drivers and pressure for sustainability from the perspective of regulations and policy makers.

The remainder of the paper is organised as follows. Section 2 critically reviews the contemporary literature on sustainability performance of SMEs and identifies knowledge gaps that this research intends to bridge. Section 3 elaborates on the methodology that we adopt to achieve the research objectives. Section 4 introduces the proposed performance measurement model/framework. Section 5 demonstrates the application of the proposed modelling approaches. Section 5 provides explicit discussion and conclusions of this paper.

\section{Literature Review}

Performance measurement (PM) is described as the process of quantifying efficiency and effectiveness of action (Neely et al. 1995) or the process of using measurement information to support managers in decision-making situations and to link strategy to operations (Bititci et al. 2012). Different PM tools have been developed in recent decades from different perspectives (Ramezankhani et al. 2018). Nudurupati et al. (2011) report that performance management is an organisation-wide shared vision that surrounds performance measurement activity. Marr and Creelman (2011) define performance management as "the execution of the organization mission through the coordinated effort of others". In the past few years, performance management has become much more common in government managed organisations (Poister 2003) and has evolved into a popular research topic in the field of management (e.g. Taticchi et al. 2010; Nudurupati et al. 2011).

Thomas and Griffin (1996) propose that supply chain management (SCM) reflects the most advanced state in the evolutionary development of purchasing, procurement and other supply chain activities. Hall (2000) argues that today's organisations face pressure to enhance sustainable behaviour from several sources, including regulations, consumers, etc. As noted also by Dey and Cheffi (2012), the pressure from various stakeholders to commit to sustainable practices and performance management results in the rapid increase of interest in sustainable supply chains and their management on the part of government regulators, NGOs, academics and industrial players. Measurement has been recognized as a crucial element to improve business performance (Sharma et al. 2005). Consequently, there has been a vast body of literature on designing and implementing performance measurement tools as well as developing sustainability performance plans in supply chains (e.g. Gunasekaran et al. 2004; Chan and Qi 2003; Shepherd and Gunter 2005; Dey and Cheffi 2013).

Gunasekaran et al. (2004) claim that performance measurement and metrics have an important role to play in setting objectives, evaluating performance, and determining future courses of action. However, they point out that performance 
measurement and metrics pertaining to SCM have not received adequate attention from researchers or practitioners. Therefore, they have developed a framework to promote a better understanding of the importance of SCM measurement and metrics. Taticchi et al. (2013) report that supply chain sustainability has been of great interest in the last decade for academia and the industrial world because of pressures from various stakeholders to adopt a commitment to sustainability practices. Chan and Qi (2003) have proposed a PM method to contribute to the development of SCM, which employs a process-based systematic perspective to build an effective model that measures the holistic performance of complex supply chains. Shepherd and Gunter (2005) have developed several metrics and classified them into different groups as follows: (a) Whether they are qualitative or quantitative, (b) What they measure (i.e. cost vs non-cost; quality, resource utilization, delivery and flexibility, visibility, trust and innovativeness), (c) Their operational, tactical or strategic focus, and (d) The process in the supply chain they relate to. Taticchi et al. (2013) have also adapted this classification of metrics.

Dey and Cheffi (2013) have developed a framework for green supply chain performance measurement consisting of two higher order constructs based on environmental practices and sustainable performances across the supply chain using the analytic hierarchy process (AHP). Bhattacharya et al. (2013) identify the green causal relationships between the constructs (i.e. organisational commitment etc.) based on a green supply chain PM framework and test them with a collaborative decision-making approach using a fuzzy analytical network process based green balanced scorecard. Bhagwat and Sharma (2007) have also applied a balanced scorecard approach for measuring and evaluating day-to-day business operations. Zhu et al. (2007a) reveal that external relationships in green supply chain management may receive less attention than might be expected. Kainuma and Tawara (2006) suggest that quantitative methods can be useful, when considering the complexity involved in making a supply chain leaner and greener, in assessing the value of specific initiatives to the overall greenness of the supply chain (Zhu et al. 2007b) or in deciding what to do first (Kleindorfer et al. 2005; Orsato 2006).

Enterprises have to measure, monitor and manage performance in multiple dimensions using a balanced and dynamic set of measures that facilitates decisionmaking processes (Nudurupati et al. 2011; Taticchi et al. 2009). Kaplan and Norton (1996) argue that the concept of "balance" refers to the need of using different metrics and perspectives, that are linked together to give a holistic view of the organization, e.g. financial versus non-financial; quantitative versus qualitative; internal versus external; etc. See also Lynch and Cross (1991); Fitzgerald et al. (1991); and Neely et al. (2002). Garengo et al. (2005) claim that the word "dynamic" implies the need of developing a system that constantly monitors the internal and external context and reviews objectives and priorities up to date. For enterprises or companies it is necessary to measure, monitor and manage organizational performance in its multiple dimensions to compete in complex and continuously changing environments. Research within this topic focuses on the ongoing development of both qualitative and quantitative metrics and frameworks (Taticchi et al. 2009).

The implementation of a performance measurement system in SMEs, especially in the manufacturing sector, has been the popular research question due to 
the important changes occurring recently, e.g. the increasingly competitive environment, the proneness of growing in dimension, the evolution of quality concept, the increased focus on continuous improvement and the significant advances in information and communication technologies (Garengo et al. 2005).

In recent years, with more and more focus shifting towards environmental protection, a rich body of literature has emerged devoted to performance measurement and green supply chains, e.g. Lee and Klassen (2008), Gavronski et al. (2011), Halkos and Polemis (2018) and Kim et al. (2011). Lee and Klassen (2008) have mapped the factors that initiated and improved environmental capabilities in small- and medium-sized enterprises over time using a case study method including multiple suppliers of two large buying firms. They point out that buyers' green supply chain management initiated and then enabled the improvement of suppliers' environmental capabilities through several specific mechanisms. Gavronski et al. (2011) have provided a model for the development of green supply chain capabilities that is grounded on the resource-based view of the firm as the theoretical background. Halkos and Polemis (2018) estimate the environmental efficiency of the power generation sector in the USA by using Window Data Envelopment Analysis (W-DEA) (see also Halkos et al. (2015a, b) for similar approaches at country level). Kim et al. (2011) have presented a model for the optimal design of biomass supply chain networks under uncertainties impacting overall profitability and design. Moreover, Bjorklund et al. (2012) have identified five dimensions of performance measurement for green supply chain: (a) stakeholder perspective, (b) purpose of measuring, (c) managerial levels of measuring, (d) measuring across the supply chain and (e) combination of measurements. Shi et al. (2012) have identified causal links between institutional drivers, intra-organisational and inter-organisational environmental practices that affect green supply chain management. Hassini et al. (2012) review the literature on sustainable supply chains during the 2000-2010 period to design an original framework for sustainable supply chain management and performance measurement, which provides a link to closed-loop supply chains incorporating sourcing, transformation, delivery, value proposition, customers and product use along with reuse, recycle and return concepts.

The above literature highlights the necessity to create an integrated framework for measuring the performance of supply chains. Walker and Jones (2012) have pointed out that there is a wide gap between what practitioners say and actually do about the sustainability of supply chains because they only provide lip service to sustainable supply chain management.

To the authors' knowledge, there is a rather limited volume of published studies on benchmarking the performance of sustainable supply chains using DEA as the quantitative tool. Wong and Wong (2007) employ DEA for measuring supply chain performance and Azadia et al. (2015) have developed a DEA-based model that allows evaluation of suppliers in sustainable supply chain management. Although DEA is capable of segregating efficient and inefficient SMEs with respect to sustainability performance and suggest improvement measures solely for inefficient SMEs, it is unable to recommend improvement actions for the efficient SMEs or to come up with relationships between sustainability criteria and sustainability performances 
that can be generalized for the entire population of SMEs based on the statistical analysis of a specific sample.

On the other hand, SEM is able to establish correlations among all the criteria by formulating a PM model. Using this model, suitable steps for improving the sustainability performance of both efficient and inefficient SMEs could be undertaken in a more unified way. This research utilises the pros of both DEA and SEM. While DEA classifies SMEs into efficient and inefficient ones in line with their sustainability performance, SEM puts forward improvement measures for every SME within the region. This combined information may help both policy makers and SME owners/ managers.

Another comparative advantage of the combined use of SEM and DEA analysis is feeding DEA with more suitable overall input and output data of latent constructs through SEM, instead of the typical approach of averaging or aggregating individual observed variables.

\section{Methodology}

The proposed research processes commence with an in-depth literature review on climate change issues and environmental practices of small and medium-sized enterprises across the world in order to identify issues and challenges facing them, policies being adopted, strategies being deployed and framework being used for achieving superior environmental performance. Specifically, the study undertakes the following steps: (a) reviewing literature to identify constructs for supply chain characteristics and sustainability performance measurement of SMEs, (b) developing a questionnaire to derive supply chain characteristics of SMEs, (c) selecting SMEs for survey and performance measurement, and conducting the survey with the selected SMEs, (d) formulating a DEA-based supply chain sustainability PM model, (e) processing the data to feed into the SEM and DEA models, (f) running the SEM models and suggesting improvement initiatives for the participating SMEs by using SEM, (g) running the DEA models and deriving the supply chain sustainability performance of the participating enterprises and $(h)$ deriving a set of propositions from the research. Figure 1 represents the research method framework.

The following paragraphs describe the collected data and subsequently demonstrate the methods (SEM and DEA) that have been considered for developing the proposed performance measurement and benchmarking framework.

\subsection{Sample Collection and Data}

For the purposes of the current research, a questionnaire has been constructed in order to study the sustainability practices and performance of a number of French and British SMEs. The analysis and outcome of the questionnaire survey into SMEs covering aspects such as manufacturing, processing and construction help develop a sustainability PM and management framework. This framework is then applied to a sample of selected companies in the UK (30 SMEs) and 


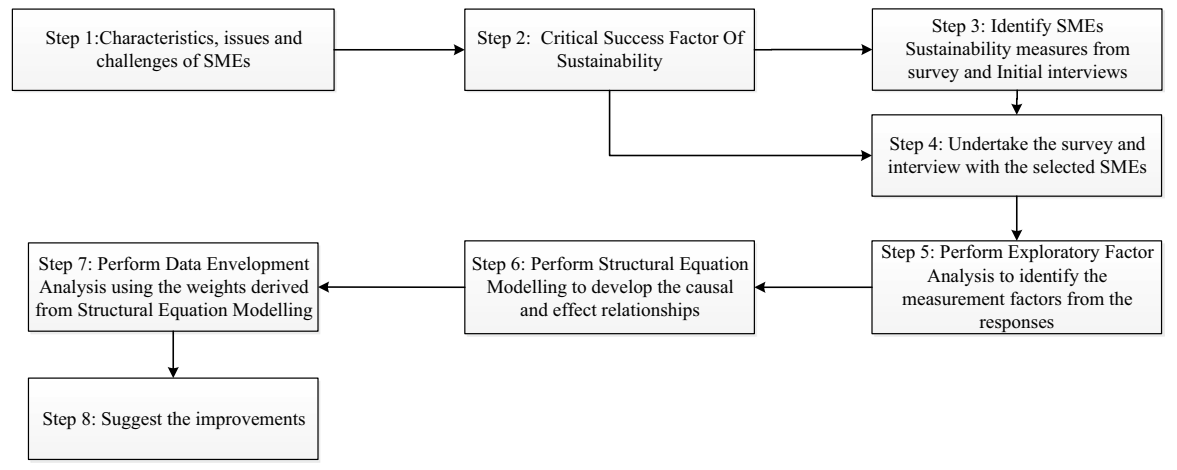

Fig. 1 Research method framework

France (54 SMEs) to measure their current sustainable performance using combined structural equation modelling and data envelopment analysis and suggest improvement measures through SEM. The sample of SMEs is from operating sectors whose environmental impact is generally stronger compared with SMEs in other sectors.

Specifically, an interview protocol was formed and the survey was designed and conducted aiming at capturing the perceptions of the SME owners and managers about the sustainable supply chain practices and performance of SMEs in the UK and France. Initially a workshop was organized with the involvement of selected researchers and owners/managers of a small number of SMEs to derive the suitable questionnaire for achieving the objectives of the study. Secondly, an initial pre-sample survey was carried out into some SMEs in the Midlands, UK, and Normandy, France. Sample size selection for our sample framework has been determined by utilizing simple random sampling, where we have used $\hat{p}=0.5$ as an estimate of population proportion that shares a certain characteristic on one of the (categorical) variables in the survey, $e=10 \%$ the proportion of error we are prepared to accept and $t=1.96$ the value from the standard normal distribution reflecting the $95 \%$ confidence level, indicating a sample size of approximately 90 companies.

An interview protocol has been created for capturing the supply chain characteristics of SMEs (available on demand) through the aforementioned questionnaire. This helps identify criteria and sub-criteria for the supply chain sustainability performance of the SMEs under investigation. Table 1 shows the criteria and sub-criteria of the proposed DEA-based PM model and SEM model for establishing relationships among the criteria that have been set through questionnaires. Practices are considered as inputs and performances are the outputs. In order to obtain a unified index for the corresponding practices/performances that can subsequently be entered as inputs and outputs into the DEA model, we have utilized factor scores derived from SEM analysis. Detailed information on the relevant literature studied for the selection of the specific indicators is provided in Table 5 in the "Appendix". 
Table 1 Criteria and sub-criteria for input and output

\begin{tabular}{ll}
\hline Practices & Performance \\
\hline Economic & Economic \\
1. Number of Employees (ECO_PR_1) & 1. Turnover (ECO_PER_1) \\
2. Infrastructure (ECO_PR_2) & 2. Business growth (ECO_PER_2) \\
Environmental & Environmental \\
1. Adopting standardized environmental system & 1. Effectiveness of environmental system (ENV_ \\
(ENV_PR_1) & PER_1) \\
2. Waste management practices (ENV_PR_2) & 2. Waste reduction (ENV_PER_2) \\
3. Energy consumption and emission control & 3. Reduction energy consumption and emissions \\
(ENV_PR_3) & (ENV_PER_3) \\
Social & Social \\
1. CSR practices (SOC_PR_1) & 1. CSR performance (SOC_PER_1) \\
2. Health and safety practices (SOC_PR_2). & 2. Health and safety performance (SOC_PER_2) \\
Operational & Operational \\
1. CRM practices (OPR_PR_1) & 1. Long term relationship with customers (OPR_ \\
2. SRM practices (OPR_PR_2) & PER_1) \\
3. Standardized business process (OPR_PR_3) & 2. CRM effectiveness (OPR_PER_2) \\
4. Lean practices (OPR_PR_4) & 3. Demand uncertainties (OPR_PER_3) \\
& 4. Long term relationship with supplier (OPR_PER_4) \\
& 5. SRM effectiveness (OPR_PER_5) \\
& 6. Supply uncertainty (OPR_PER_6) \\
7. Business process effectiveness (OPR_PER_7) & 8. Lean effectiveness (OPR_PER_8) \\
\hline
\end{tabular}

\subsection{Analysis Based on Combined SEM and DEA}

The two stages of the analysis are presented in this section. In the first stage, SEM is applied to the observed items of sustainability practices and performances illustrated in Table 1, to derive the overall associations between practices and performances in the two countries. In addition, the latent factor scores of sustainability inputs (sustainability practices) and outputs (sustainability performances) are extracted in order to be subsequently used for the DEA analysis. In the next stage, DEA analysis is run based on inputs/outputs obtained through SEM. The methodologies used in this analysis are briefly described below.

\subsubsection{Structural Equation Modelling}

In order to test the influence of the various latent items of sustainability practices on the sustainability performance of SMEs, we fit two structural equation models (see Bollen 1989), one for the French and one for the British data. Specifically, we hypothesize a unified conceptual sustainability model where the four latent constructs of sustainability practices (i.e. economic, environmental, social and operational) are causing the four corresponding latent constructs of sustainability performance (see Fig. 2).

The distinguishing characteristic of SEM is that variables can be either directly observed or latent or a mixture of both like the eight latent constructs of 


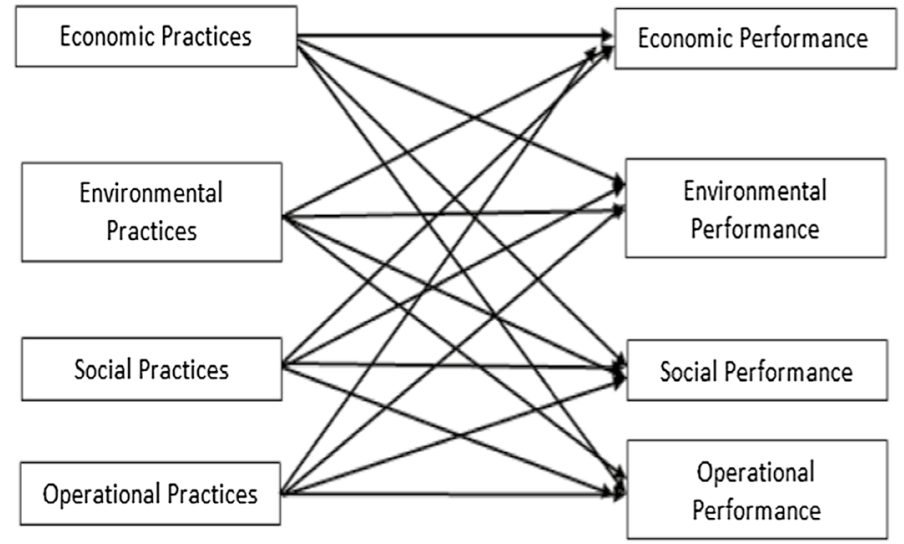

Fig. 2 Conceptual model for SEM analysis

sustainability practices and performances), a feature that cannot be found in other standard regression-type analysis techniques, such as multiple regression analysis.

By combining each latent sustainability factor of practices and performances with the corresponding observed items obtained from the questionnaire data and associating all latent constructs of practices with all latent constructs of performances we derive the hypothetical model of Fig. 2. This model is fitted, separately to the French and British data, by the method of Weighted Least Squares (WLS) (Jöreskog 1994) due to the discrete nature of the observed collected data. Fit of the two models was performed with the use of Amos statistical software (Arbuckle 2014).

As regards assessing the fit of a SEM model, there exists a large variety of goodness-of-fit measures that are mostly functions of the model's Chi square. Typical examples of such indices are the GFI (goodness-of-fit index) and the AGFI (adjusted goodness-of-fit index). Another popular measure is the Root Mean Square Error of Approximation (RMSEA). If the fit of the model is good, GFI and AGFI should approach 1, whereas RMSEA should be small (typically less than 0.05).

\subsubsection{Data Envelopment Analysis}

The DEA method (Charnes et al. 1978; Banker et al. 1984) is a linear programming technique, based on relative efficiency. The major advantage of DEA is that it is applicable to situations with many inputs and outputs without any prior information on weights. To gain a better understanding of the idea of DEA, the singleinput single-output case is most intuitive (see Fig. 3). Let us suppose there is a Decision Making Unit (DMU) $K$ producing certain outputs with given inputs using the technology that is defined by the curve "True frontier", which, unfortunately, is not observable. DEA frontiers are proved to be the maximum likelihood estimation of "True frontier" (see e.g. Banker 1993; Cao et al. 2016) under certain assumptions (Korostelev et al. 1995). It is obvious that $K$ is not efficient since it could produce the same output with much less input. Thus, its inefficiency can be measured 
Fig. 3 The illustration of production frontiers

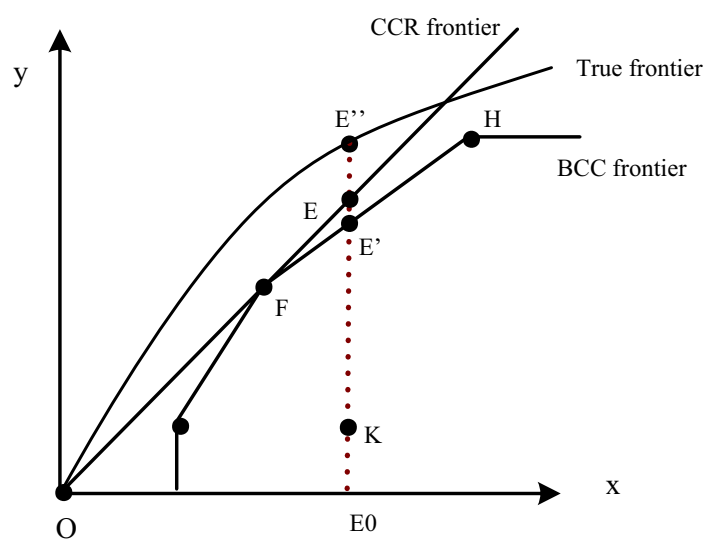

from the relative distance towards the frontier. In input direction it is the factor by which the inputs could be downscaled-so that $K$ would lie on the frontier. However, in real cases, the true frontier is not observable so this measure cannot be calculated directly. The basic idea of DEA is grounded in estimating the unobserved true frontier by a frontier which is constructed from existing observations. The model (CCR model) developed by Charnes et al. (1978) assumes constant returns to scale (RTS), which implies that the frontier is a straight line from the origin. Under a variable RTS assumption, Banker et al. (1984) proposed the BCC model with an extra convex constraint. The BCC frontier is the one formed by the line segment EFH in Fig. 3.

Under different returns to scale assumptions, the derived efficiencies of certain DMUs can vary. In Fig. 3, true efficiency, output-based CCR efficiency and BCC efficiency of unit $K$ can be represented as reciprocals of $E^{\prime \prime} E_{0} / K E_{0}^{\prime}, E E_{0} / K E_{0}$ and $E^{\prime} E_{0} / K E_{0}$, respectively. Furthermore, we can easily see that CCR efficiency and BCC efficiency will by construction overestimate true efficiency (See also Cao et al. 2016; Shen et al. 2016). However, it has been proved that if the sample becomes large, the estimated frontier converges to the true one (e.g. Smith 1997; Kneip et al. 2008).

Using the DEA analysis, a specific DMU (i.e. a SME in our application) can enhance its sustainability performance by setting its projection on the frontier as the performance target. For the purposes of the current analysis, the BCC-DEA modelling approach has been employed.

\subsubsection{Combining SEM factor scores as inputs/outputs for DEA analysis}

The combined application of SEM and DEA involves the introduction of raw factor score values of practices and performances latent structures estimated by the fit of weighted least squares SEM models into the BCC-DEA models. However, due to the specific nature of raw factor scores from SEM analysis, which involve positive and also negative (small in magnitude) values, there are methodological issues that arise in the context of DEA analysis, which are associated with this data divergence. 
To this end, and following the suggestions of the relevant theoretical literature (Ali and Seiford 1990), the factor score data are normalised to comply with the suitable scale of the data for DEA analysis. Hence the normalisation of the SEM results is carried out and subsequently fed into the DEA models.

The results of the SEM analysis (i.e. raw SEM factor scores) are attached in "Appendix" 6 and 7 for the British and French SMEs, respectively. These results are transformed by scaling data into the DEA model. The data transformation has been performed through the following equation:

$$
\text { Data transformation }=1-\frac{\text { data }-\min \text { data }}{\max \text { data }-\min \text { data }}
$$

The obtained transformed data are then put into the DEA conceptual model. The results of the DEA analysis are shown in Tables 8 and 9 for the British SMEs and similarly Tables 10 and 11 for the French SMEs.

\section{Application}

Supply chain data were gathered from SME representatives in two specific geographical locations (Normandy in France and Midlands in the UK) in order to validate the effectiveness of the proposed method. The information was collected through the specially constructed interview protocol (questionnaire utilized for the study is available upon request by the corresponding author). The responses were processed via SEM models in order to subsequently be fed into the DEA models for each input and output criterion. In the following sub-sections, the results derived from the combined application of SEM and DEA methods on the SME sample are presented in detail.

\subsection{Deriving Associations Between Sustainability Practices and Performance of SMEs Through SEM Modelling}

SEM enables developing relationships between the criteria and sub-criteria for a sustainability performance measurement that facilitates to identify improvement measures for every SME within a region through a statistical modelling approach. Additionally, the obtained weighted estimates - in the form of factor scores - of the overall constructs of sustainability practices and performances can be utilized for the subsequent DEA analysis.

Here we present the results of the fit of SEM models to the French and British data. In particular, the SEM results of the British and French SMEs are depicted in Figs. 4 and 5 respectively, where one can see the standardized coefficients of the associations between sustainability practices and the corresponding performances.

As is seen from the obtained results, in the region of Midlands, UK, the economic practices of SMEs are interconnected with their economic, environmental and operational performance; and each set of practices is linked to each type of performance respectively (Fig. 4). Therefore, any given SME located in the Midlands 


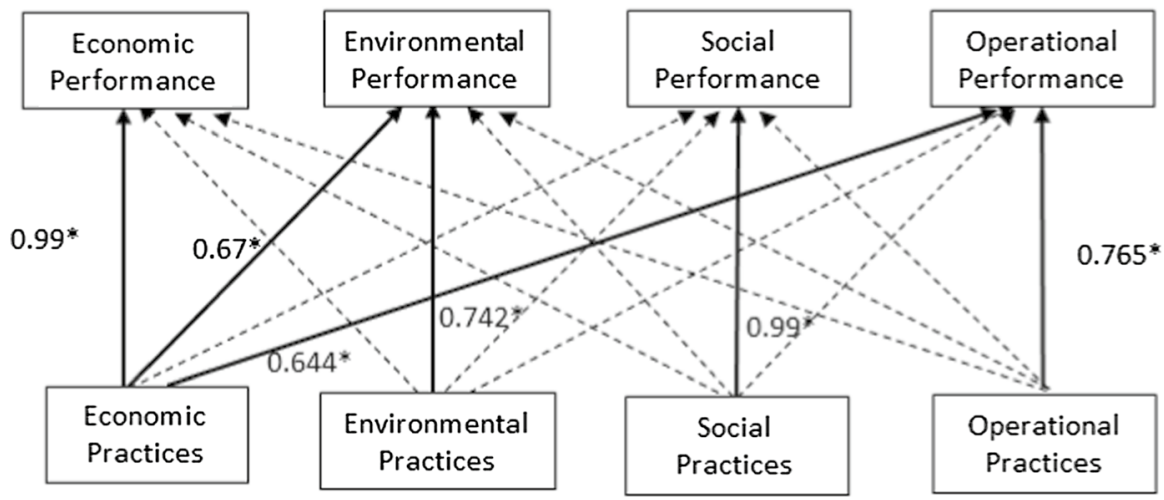

Fig. 4 Estimated SEM Model (British data). ${ }^{*} p<0.05$; Solid right arrow: significant direct positive effect; Dashed right arrow: non-significant direct effect

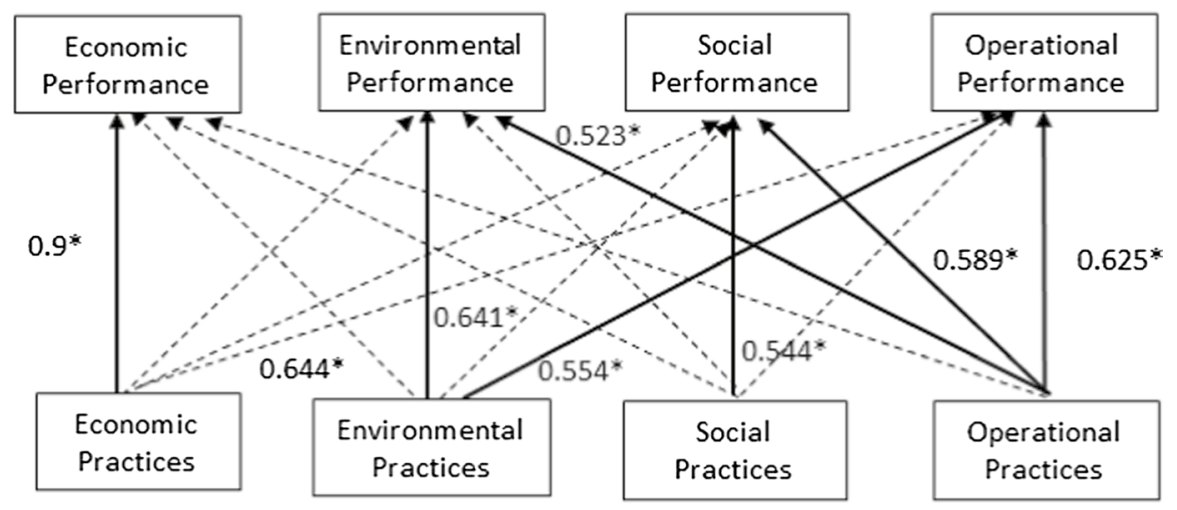

Fig. 5 Estimated SEM Model (French data). ${ }^{*} p<0.05$; Solid right arrow: significant direct positive effect; Dashed right arrow: non-significant direct effect

is quite likely to enhance its economic, environmental and operational performance through effective management of economic practices. However, in order for SMEs to improve their social performance they are required to address their social practices closely.

On the contrary, as regards the French SMEs, economic practices are connected only to their economic performance (Fig. 5). Operational practices have a strong correlation with operational, environmental and social performances; environmental practices are associated with both environmental and operational performances. Therefore, SMEs in Normandy, in order to optimize their environmental and social performance, need to address all operational, environmental and social issues and challenges. Additionally, improving environmental practices will contribute to a higher operational performance. However, economic performance only depends on economic practices and remains unaffected by any other variable. 
The information generated from SEM analysis makes it possible for both policy makers and individual SME owners/managers to upgrade their company's performance. Additionally, both efficient and inefficient SMEs remain informed on their performance dynamically. Even SMEs that have not taken part in the analysis can gain valuable insights from supply chain practices and performances of enterprises in their region, a fact that will ultimately help them to re-examine their practices and performance in order to make the right decisions.

\subsection{Benchmarking Inefficient SMEs Through DEA}

In the current section, the results of DEA analysis utilizing the input and output scores derived via SEM are presented in detail. Specifically, Tables 6 and 7 in "Appendix" include British and French SMEs' input/output data respectively, referring to the raw factor scores obtained through SEM. Tables 2 and 3 show the efficient and inefficient SMEs of the UK and France respectively, following application of the DEA method. In Table 2, we can see that, as per the above data analysis using VRSTE, the UK SMEs coded as 3, 4, 6, 8, 11, 13, 14, 15, 16, 18, 19, 21, 23, 24, 26, 27, 29 and 30 are efficient. There are 12 inefficient SMEs according to the BCCDEA model. There are 1,13 and 16 SMEs with increasing returns to scale (IRS), constant returns to scale (CRS), and decreasing returns to scale (DRS), respectively. Column 4 in Table 2 shows the scale efficiencies of those 30 British SMEs.

In Table 3, which shows the efficiency summary of the participating French SMEs, we can see that, as per the above data analysis using VRSTE, there are 30 French SMEs which are efficient, whereas there are 24 inefficient SMEs according to the BCC-DEA model. There are 0, 28, and 26 French SMEs with increasing returns to scale (IRS), constant returns to scale (CRS), and decreasing returns to scale (DRS), respectively. Column 4 in Table 3 shows the scale efficiencies of those 54 French SMEs (see also Fig. 6 for a comparative graph for the two countries' SMEs).

Tables 8, 9, 10 and 11 in "Appendix" include the slacks and targets of the inefficient British and French SMEs of our sample, respectively. The term 'slacks' refers to the residues of the variables in DEA model. The input and output targets denote the benchmarks for performance improvement of assessed SMEs.

In order to demonstrate the usefulness and applicability of the DEA analysis performed in combination with structural equation modelling, Table 4 shows an illustrative example based on the detailed results of randomly chosen DMU in the UK (DMU1) that pinpoints how important it is to suggest actions for improving the performance of the specific inefficient company.

Original values against each economic, operational, environmental and social practice and performance in line with survey responses are shown in row 1 of the Table. The difference $\%$ in the third row shows that the movement desired in input is $4.8 \%$, indicating that a decrease is required. The final projected value for achieving efficiency is shown in row 2 for economic, operational, environmental and social performances respectively.

Similar analysis was undertaken for all the inefficient SMEs and improvement measures were derived. These measures enable the enterprises to develop 
Table 2 Efficiency summary of 30 UK SMEs

\begin{tabular}{|c|c|c|c|}
\hline SMEs & Scale efficiency & Rank & Returns to scale \\
\hline DMU 1 & 0.952 & 19 & CRS \\
\hline DMU 2 & 0.505 & 29 & DRS \\
\hline DMU 3 & 1 & 1 & DRS \\
\hline DMU 4 & 1 & 1 & CRS \\
\hline DMU 5 & 0.874 & 23 & DRS \\
\hline DMU 6 & 1 & 1 & CRS \\
\hline DMU 7 & 0.584 & 28 & CRS \\
\hline DMU 8 & 1 & 1 & DRS \\
\hline DMU 9 & 0.929 & 20 & DRS \\
\hline DMU 10 & 0.733 & 25 & CRS \\
\hline DMU 11 & 1 & 1 & CRS \\
\hline DMU 12 & 0.892 & 22 & DRS \\
\hline DMU 13 & 1 & 1 & CRS \\
\hline DMU 14 & 1 & 1 & CRS \\
\hline DMU 15 & 1 & 1 & DRS \\
\hline DMU 16 & 1 & 1 & DRS \\
\hline DMU 17 & 0.908 & 21 & DRS \\
\hline DMU 18 & 1 & 1 & CRS \\
\hline DMU 19 & 1 & 1 & DRS \\
\hline DMU 20 & 0.645 & 26 & DRS \\
\hline DMU 21 & 1 & 1 & CRS \\
\hline DMU 22 & 0.604 & 27 & DRS \\
\hline DMU 23 & 1 & 1 & CRS \\
\hline DMU 24 & 1 & 1 & IRS \\
\hline DMU 25 & 0.259 & 30 & DRS \\
\hline DMU 26 & 1 & 1 & CRS \\
\hline DMU 27 & 1 & 1 & DRS \\
\hline DMU 28 & 0.845 & 24 & DRS \\
\hline DMU 29 & 1 & 1 & DRS \\
\hline DMU 30 & 1 & 1 & CRS \\
\hline
\end{tabular}

(1) IRS, CRS, and DRS denote increasing returns to scale, constant returns to scale, and decreasing returns to scale, respectively; (2) CRSTE, VRSTE denote the efficiencies in CCR and BCC, respectively

business cases through benchmarking against the practices of the specific benchmarked SMEs.

The efficient SMEs might also have room for improvement, but the DEA-based approach is unable to suggest improvement plans in terms of BCC-efficiency in the BCC-DEA model. However, those BCC-efficient DMUs could still improve their performance by (1) improving scale efficiencies, and (2) retaining unity pure technical efficiency. 
Table 3 Efficiency summary of 54 French SMEs

\begin{tabular}{|c|c|c|c|}
\hline SMEs & Scale efficiency & Rank & Returns to scale \\
\hline DMU 1 & 1 & 1 & CRS \\
\hline DMU 2 & 1 & 1 & CRS \\
\hline DMU 3 & 1 & 1 & CRS \\
\hline DMU 4 & 1 & 1 & CRS \\
\hline DMU 5 & 1 & 1 & CRS \\
\hline DMU 6 & 1 & 1 & CRS \\
\hline DMU 7 & 1 & 1 & DRS \\
\hline DMU 8 & 1 & 1 & IRS \\
\hline DMU 9 & 0.654 & 49 & DRS \\
\hline DMU 10 & 1 & 1 & CRS \\
\hline DMU 11 & 1 & 1 & CRS \\
\hline DMU 12 & 1 & 1 & CRS \\
\hline DMU 13 & 0.854 & 44 & DRS \\
\hline DMU 14 & 1 & 1 & DRS \\
\hline DMU 15 & 1 & 1 & DRS \\
\hline DMU 16 & 1 & 1 & CRS \\
\hline DMU 17 & 0.539 & 53 & DRS \\
\hline DMU 18 & 0.871 & 43 & DRS \\
\hline DMU 19 & 1 & 1 & CRS \\
\hline DMU 20 & 0.706 & 47 & DRS \\
\hline DMU 21 & 1 & 1 & CRS \\
\hline DMU 22 & 1 & 1 & IRS \\
\hline DMU 23 & 1 & 1 & CRS \\
\hline DMU 24 & 1 & 1 & CRS \\
\hline DMU 25 & 0.619 & 52 & DRS \\
\hline DMU 26 & 1 & 1 & DRS \\
\hline DMU 27 & 1 & 1 & CRS \\
\hline DMU 28 & 0.623 & 51 & DRS \\
\hline DMU 29 & 1 & 1 & CRS \\
\hline DMU 30 & 1 & 1 & IRS \\
\hline DMU 31 & 0.712 & 46 & DRS \\
\hline DMU 32 & 1 & 1 & CRS \\
\hline DMU 33 & 0.392 & 54 & IRS \\
\hline DMU 34 & 0.826 & 45 & DRS \\
\hline DMU 35 & 1 & 1 & DRS \\
\hline DMU 36 & 0.977 & 41 & DRS \\
\hline DMU 37 & 1 & 1 & DRS \\
\hline DMU 38 & 1 & 1 & CRS \\
\hline DMU 39 & 1 & 1 & CRS \\
\hline DMU 40 & 1 & 1 & CRS \\
\hline DMU 41 & 0.932 & 42 & DRS \\
\hline DMU 42 & 1 & 1 & CRS \\
\hline DMU 43 & 0.646 & 50 & DRS \\
\hline
\end{tabular}


Table 3 (continued)

\begin{tabular}{llcl}
\hline SMEs & Scale efficiency & Rank & Returns to scale \\
\hline DMU 44 & 1 & 1 & CRS \\
DMU 45 & 1 & 1 & CRS \\
DMU 46 & 1 & 1 & DRS \\
DMU 47 & 1 & 1 & CRS \\
DMU 48 & 1 & 1 & CRS \\
DMU 49 & 1 & 1 & CRS \\
DMU 50 & 1 & 1 & CRS \\
DMU 51 & 1 & 1 & IRS \\
DMU 52 & 1 & 1 & IRS \\
DMU 53 & 1 & 1 & DRS \\
DMU 54 & 0.696 & 48 & DRS \\
\hline
\end{tabular}

Fig. 6 Distributions of the three RTS types, by country

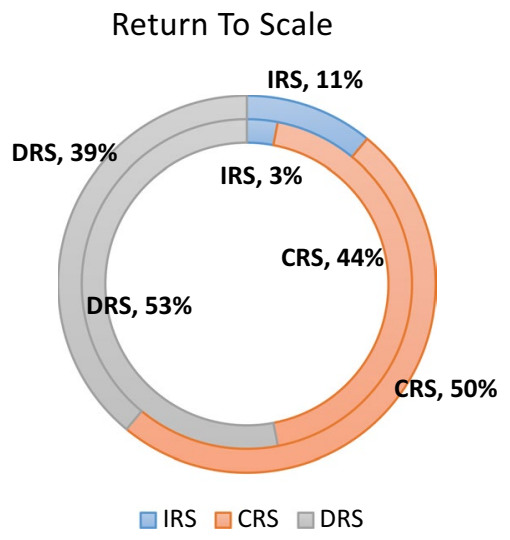

\section{Discussion and Conclusions}

This research theoretically contributes to the relevant literature by proposing a new supply chain sustainability performance measurement and management framework for small and medium-sized enterprises. At the same time, it empirically determines the state of economic, operational, social, and environmental practices and performance of the participating SMEs, and puts forward for consideration a set of improvement measures through benchmarking against sectoral best practice. Prior research on sustainability PM relies on economic, environmental and social criteria. We have added operational criteria, too, so as to objectively derive improvement measures across business processes along with resources and infrastructures. The proposed sustainable supply chain PM model combines SEM and DEA methodologies. We have clearly presented all the practices as inputs and all the performances as outputs in an effective way, by combining the methods of SEM and DEA analyses. Specifically, the combined SEM and DEA analysis has offered the ability to 


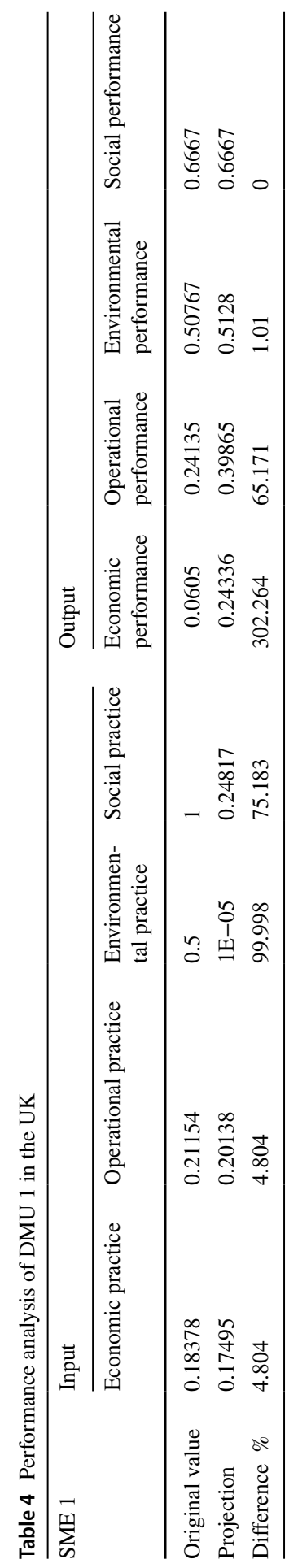


extract through SEM suitable overall input and output latent constructs of sustainability practices and performances. This approach is more robust in comparison with the typical method of using averages for derivation of a unified input/output score for each sustainability practice/performance, since it produces a suitably adjusted overall index of each construct of sustainability practices/performances (i.e. environmental, social, economic and operational) that is weighted according to the magnitude of the effect of each individual observed item on the corresponding latent structure of sustainability. This also helps to derive improvement measures through specific interventions in each practice for achieving the desired performance. Moreover, this is the first model proposed for DEA-based sustainability supply chain PM for SMEs.

The proposed combined modelling approach is validated through applications in two varied set-ups-Midlands in the UK and Normandy in France. While DEA can segregate efficient and inefficient units (i.e. individual SEMs) using a number of input and output criteria, and recommend improvement measures for inefficient units through benchmarking them against the most efficient units, complementary SEM helps to develop causal relationships among the criteria through hypotheses testing, which also enables SMEs to decide on how to enhance their performance effectively. Individual SMEs would be able to adopt this model and measure their current state of practices and performance, and accordingly implement targeted improvement initiatives. Additionally, the tool will be beneficial to policy makers as it cannot only depict the state of SMEs' sustainability in a specific region but also predict the characteristics of a specific SME's sustainable performance even if it is not included in the sample.

Although prior research has used DEA (West 2014) and SEM (Hanim et al. 2017) for sustainability analysis separately, as of today, the two methods have not been used in an integrated way so as to get the benefits of both of them and reduce the individual shortcomings of both DEA and SEM. According to the authors' knowledge, this is the first attempt to combine DEA and SEM for sustainability performance measurements.

Any group of SMEs with the objective of benchmarking their sustainability performance could adopt this model. Firstly, it is required that a consensus be reached on the input and output criteria and their proxies. In line with the proxies, an interview protocol is formed and all the participating SMEs are asked to respond. Their responses are processed in a spread sheet by linking them with each criterion (refer to Table 5 in the "Appendix"). This helps derive the value for each practice and performance criterion. These criteria are run in a DEA-based PM model to derive the efficiency of the participating SMEs and objective improvement measures for inefficient SMEs. This DEA-based supply chain sustainability PM method is equally suitable for policy makers as well as individual SME owners/managers. While individual participating SMEs can take advantage of the study results and develop business cases for improving their sustainability performance, policy makers can develop focused schemes in order to work towards and ensure the long-term viability of all the inefficient SMEs. 
The proposed combined DEA and SEM-based supply chain sustainability PM model for SMEs is robust. DEA analyzes the performance of participating SMEs using benchmarking principles and suggests improvement strategies for inefficient SMEs only. However, there may be room for improving the performance of efficient SMEs as well, something that the DEA model is unable to derive. On the contrary, the SEM approach helps to objectively extract the causal relationships between sustainable supply chain practices (inputs) and performances (outputs) of SMEs within a region from a sample study. The characteristics of any SME's sustainable supply chain within the study region could be estimated using the SEM approach. This enables to derive not only what to do (via DEA) but also how to do (via SEM) in order to enhance sustainability performance, irrespective of whether SMEs are efficient or inefficient (the latter being a major shortcoming of DEA).

The present study sheds light on the fact that SMEs in both regions could reduce inefficiency by optimising their economic and operational practices. SMEs in the Midlands, UK, need to do more in order to achieve sustainability than their French counterparts. Environmental aspects are also very important for achieving sustainability and most of the inefficient SMEs need to integrate the environmental dimension into their development process. Social aspects are not of as much concern as social practices and performance have a strong synergy. Overall, inefficient SMEs must adopt the lean approach (efficiency focused) in order to increase their sustainability. Efficient SMEs would attain a higher level of sustainability through adopting cost intensive approaches. Economic practices are likely to affect economic, environmental and operational performances in the Midlands, UK, whereas operational practices are likely to impact operational, environmental and social performances in Normandy, France.

Beside these managerial and policy implications, several potential avenues for future research emerge from the current study as well. Sensitivity analysis could also be undertaken with the consideration of various inputs and outputs along with modifications of their values. The modelling implementation, however, has certain limitations. We need a reasonably good number of SMEs to benchmark and establish causal relationships among the criteria and sub-criteria in addition to the present sample collected. Additional means of improvement could be in the direction of considering avenues for obtaining a more refined body of ideas for improving specific characteristics of sustainability practices and performances in individual SMEs, since that at the current state the DEA modelling of inputs/outputs is at a higher level (overall concepts of sustainability practices and performances). Therefore, the combined SEM- and DEA-based PM modelling approach could be integrated with other standalone PM models in order to lead to a more refined and robust approach. This has been kept outside the scope of this study and could be undertaken in the future.

Acknowledgements This research has received funding from the European Union's Horizon 2020 research and innovation programme under the Marie Sklodowska-Curie Grant Agreement No. 788692. The second author would like to acknowledge the support from National Natural Science Foundation of China (NSFC, No. 71671181). 
Open Access This article is distributed under the terms of the Creative Commons Attribution 4.0 International License (http://creativecommons.org/licenses/by/4.0/), which permits unrestricted use, distribution, and reproduction in any medium, provided you give appropriate credit to the original author(s) and the source, provide a link to the Creative Commons license, and indicate if changes were made.

\section{Appendix}

See Tables 5, 6, 7, 8, 9, 10 and 11.

Table 5 Bibliographic sources for the selection of practices and performances indicators

\begin{tabular}{|c|c|}
\hline Dimensions/indicators & References \\
\hline \multicolumn{2}{|l|}{ Economic practices } \\
\hline Infrastructure & Patyal and Koilakuntla (2015) \\
\hline Number of employees & Devins et al. (2004) \\
\hline \multicolumn{2}{|l|}{ Economic performance } \\
\hline Turnover & Whyman and Petrescu (2015) \\
\hline Business growth & Wolff and Pett (2006) \\
\hline \multicolumn{2}{|l|}{ Operational practices } \\
\hline CRM practices & Nguyen and Waring (2013) \\
\hline SRM practices & Pala et al. (2014) \\
\hline Standardised business process & Patyal and Koilakuntla (2015) \\
\hline Lean practices & Hu et al. (2015) \\
\hline \multicolumn{2}{|l|}{ Operational performance } \\
\hline Long term relationship with customers & Towers and Burnes (2008) \\
\hline CRM effectiveness & Nguyen and Waring (2013) \\
\hline Demand uncertainties & Quah and Udin (2011) \\
\hline Long term relationship suppliers & Wyld et al. (2012) \\
\hline SRM effectiveness & Hoejmose et al. (2013) \\
\hline Supply uncertainties & Koh and Simpson (2005) \\
\hline Business process effectiveness & Lewis et al. (2006) \\
\hline Lean effectiveness & Chay et al. (2015) \\
\hline \multicolumn{2}{|l|}{ Environmental practices } \\
\hline Adopting standardized environmental system & Su-Yol (2008) \\
\hline Waste management practices & Abdul-Rashid et al. (2017) \\
\hline \multicolumn{2}{|l|}{ Energy consumption and emission control } \\
\hline \multicolumn{2}{|l|}{ Environmental performance } \\
\hline Effectiveness of environmental system & Su-Yol (2008) \\
\hline Waste reduction & Abdul-Rashid et al. (2017) \\
\hline \multicolumn{2}{|l|}{ Reduction energy consumption and emissions } \\
\hline \multicolumn{2}{|l|}{ Social practices } \\
\hline CSR practices & Jamali et al. (2009) \\
\hline Health and safety practices & Santos (2011) \\
\hline \multicolumn{2}{|l|}{ Social performance } \\
\hline CSR performance & Fen Tseng et al. (2010) \\
\hline Health and safety performance & Groves et al. (2011) \\
\hline
\end{tabular}




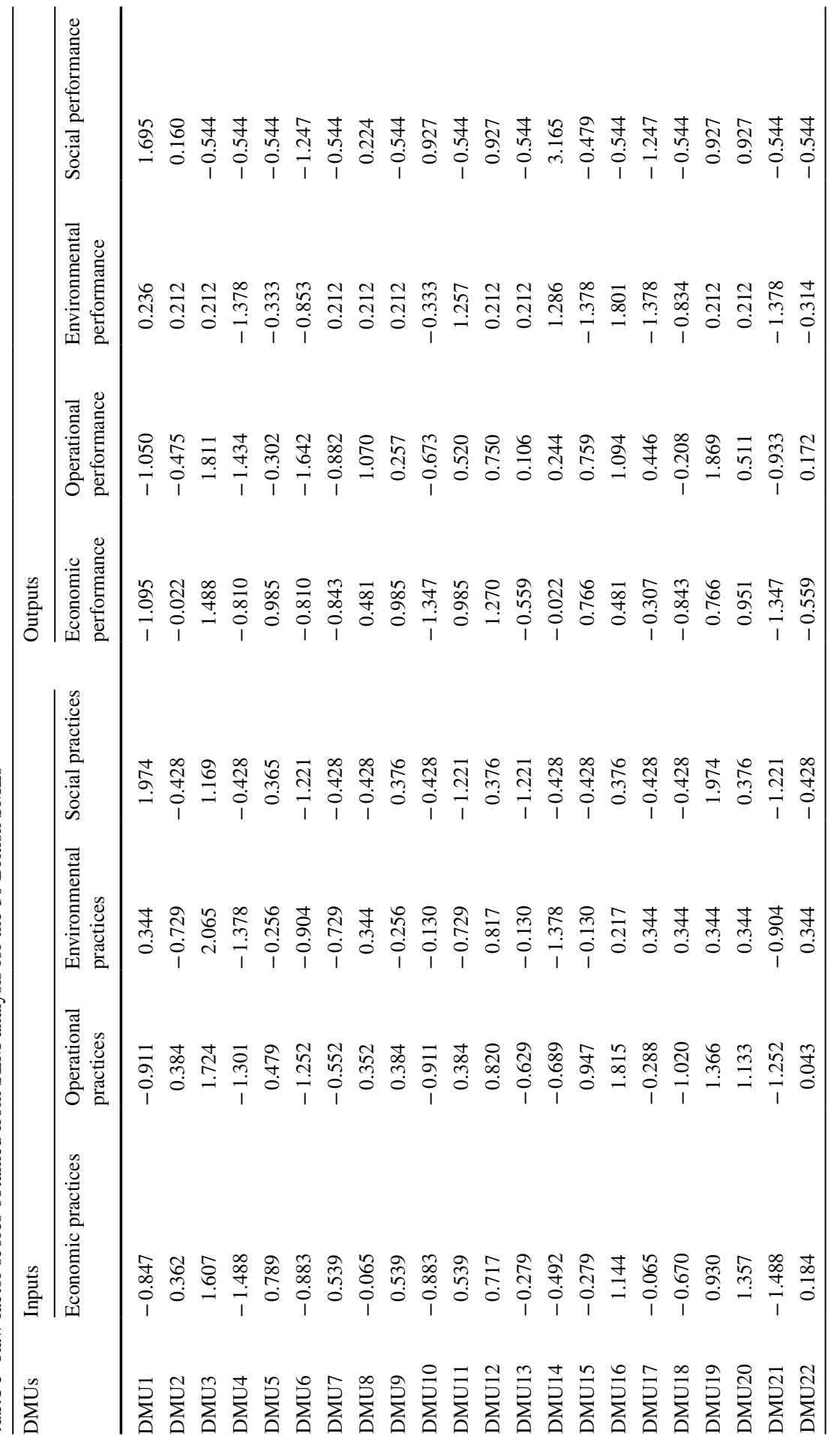




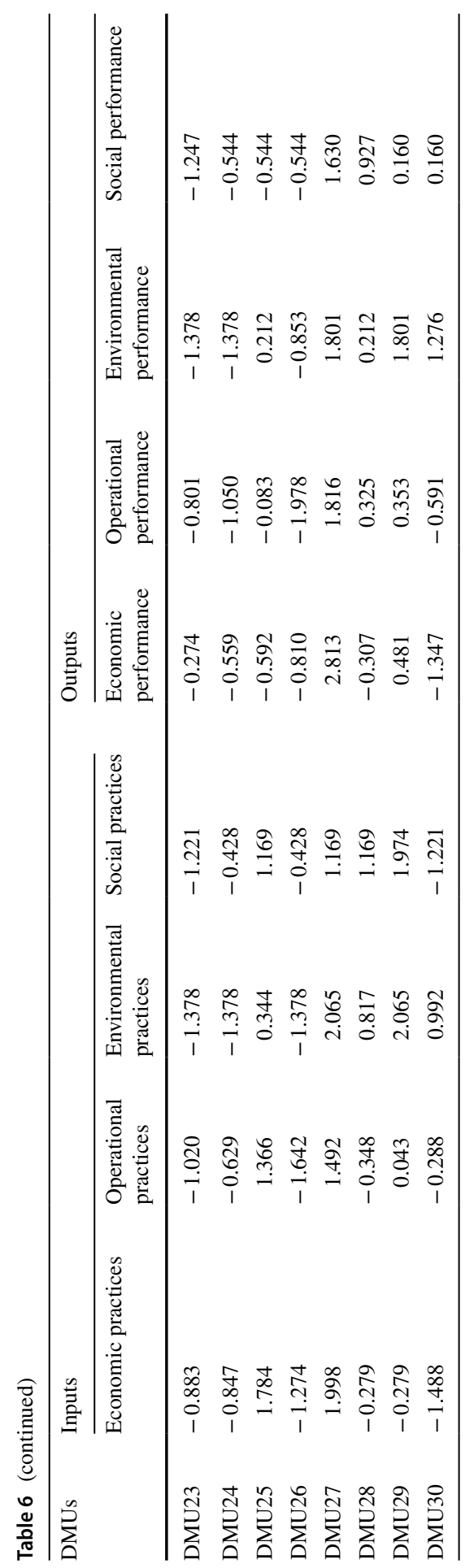




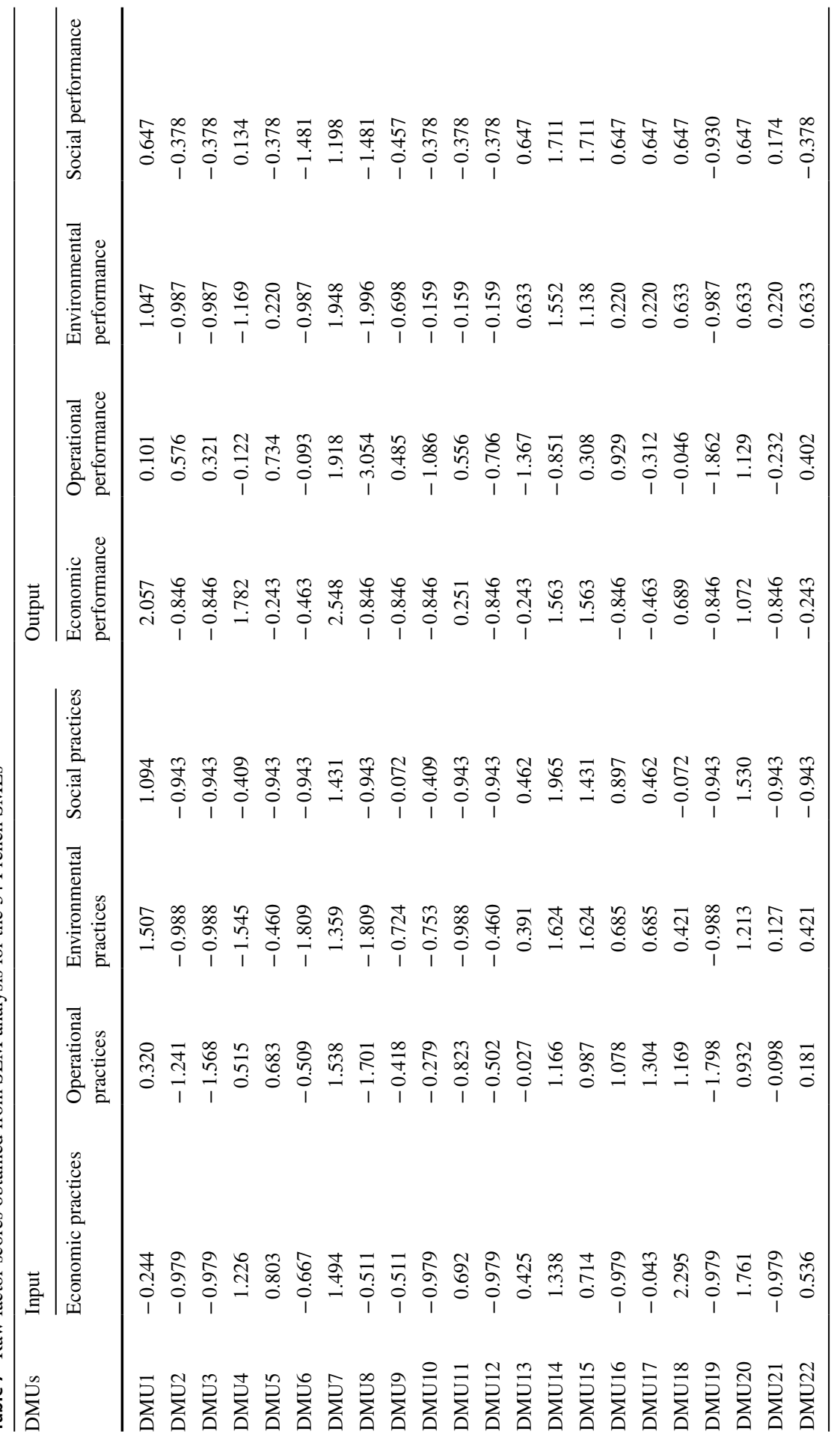




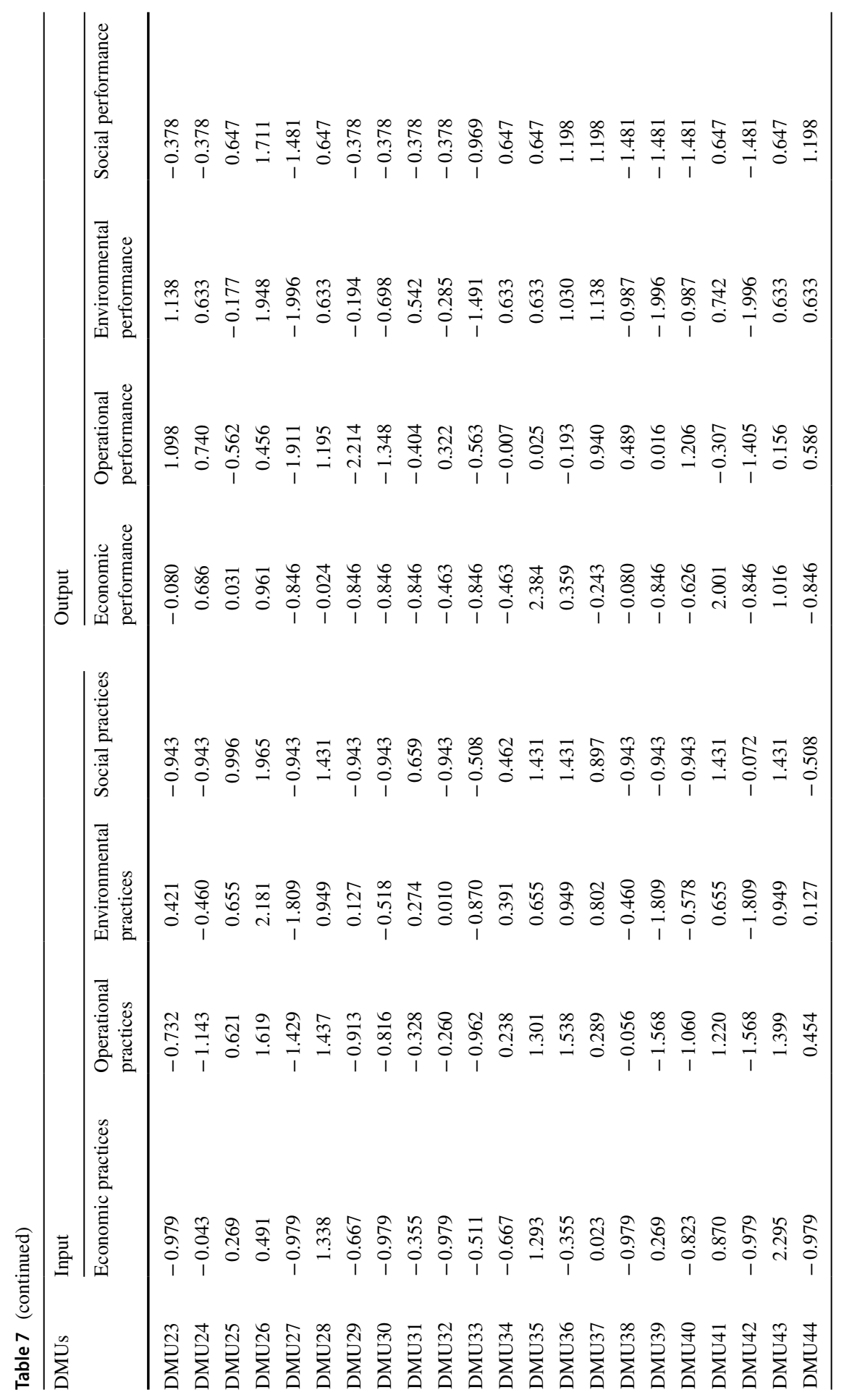




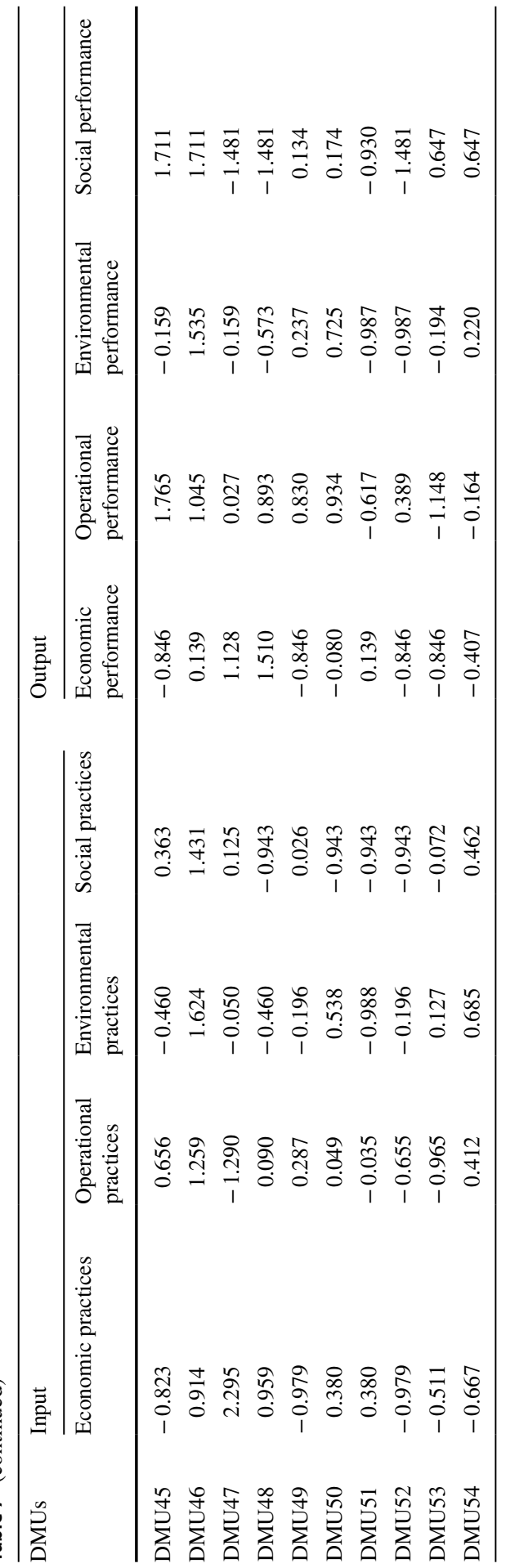




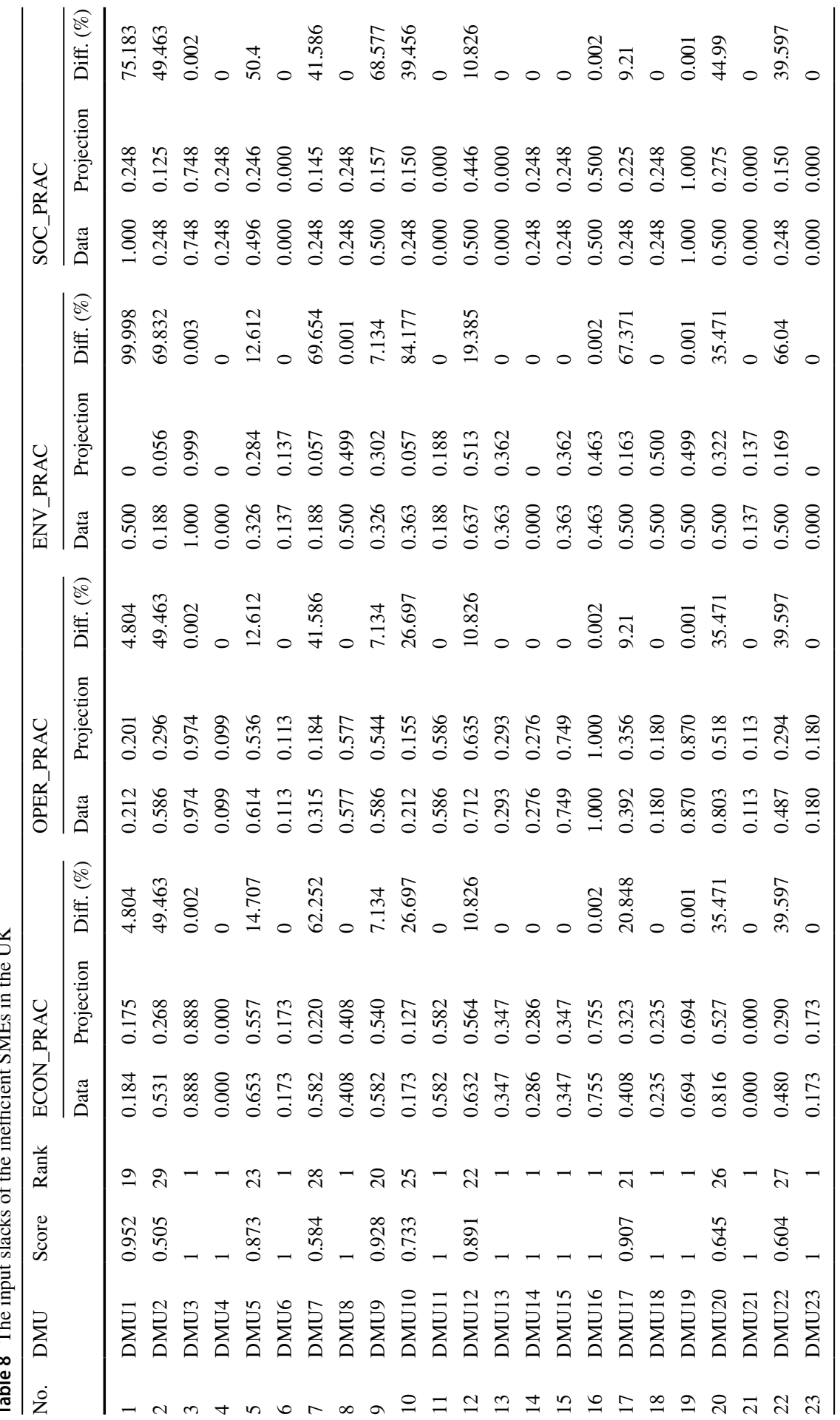




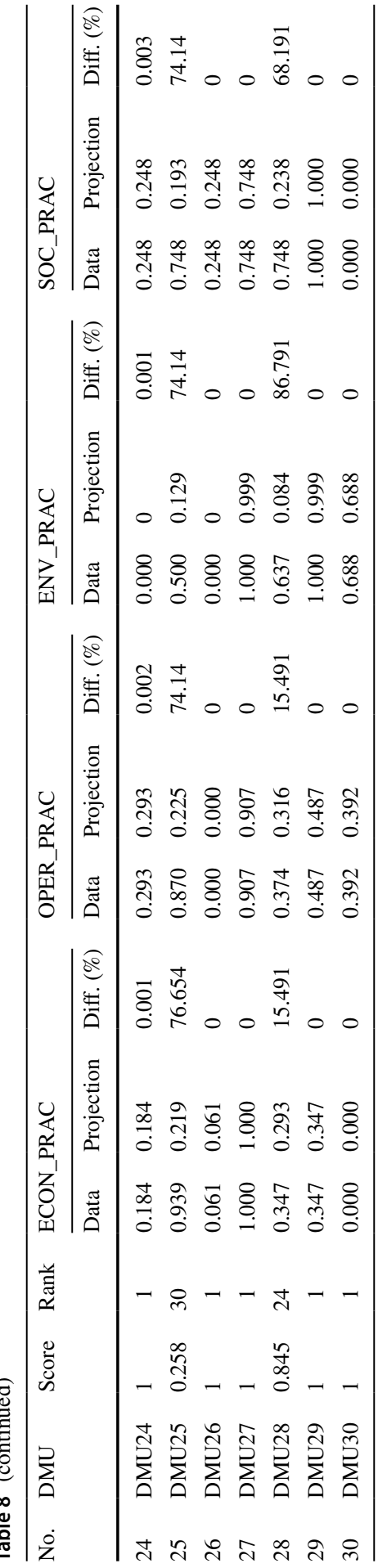




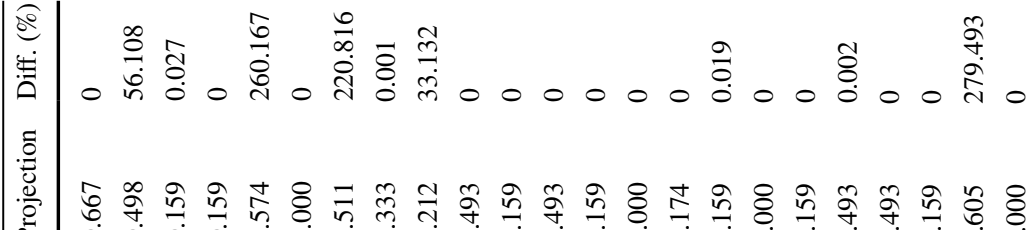
范

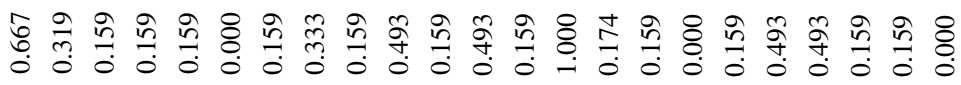

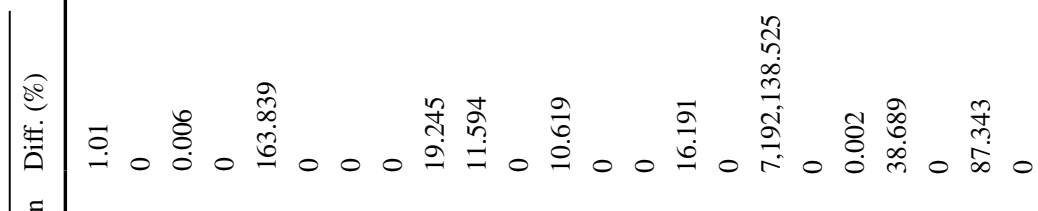
.륭

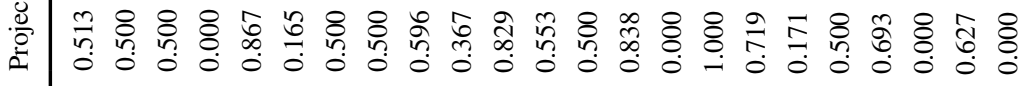

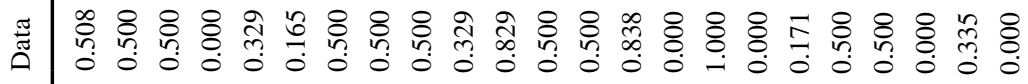
|

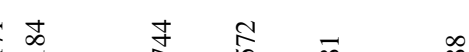

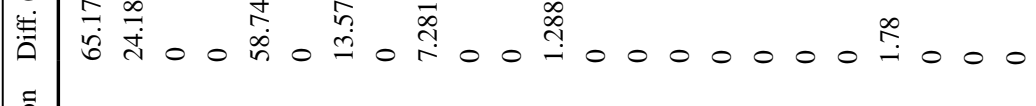
오ํ

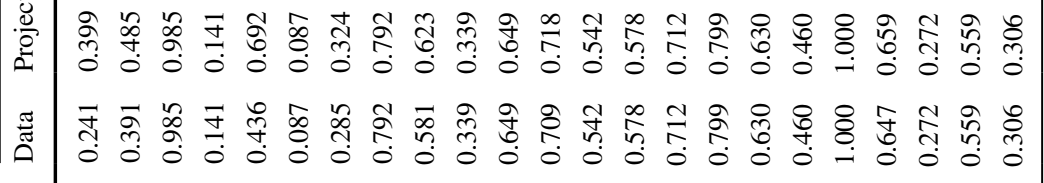
กิ है

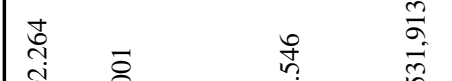
(n)

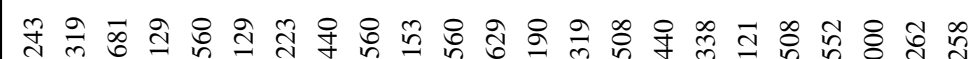
ते

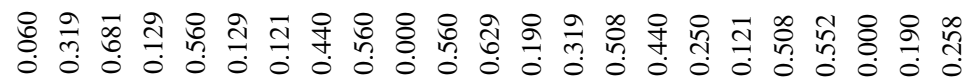

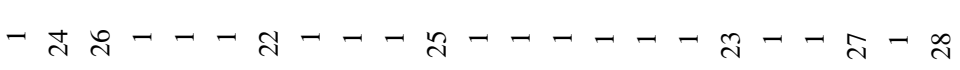

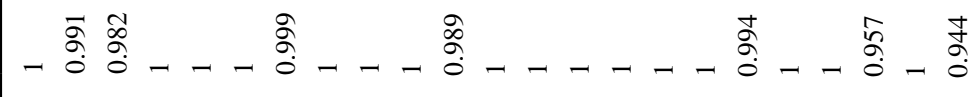

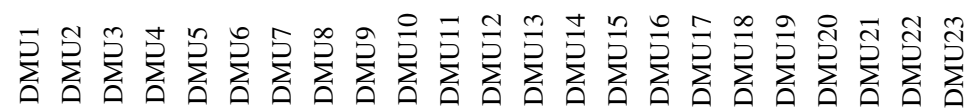

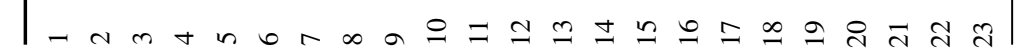




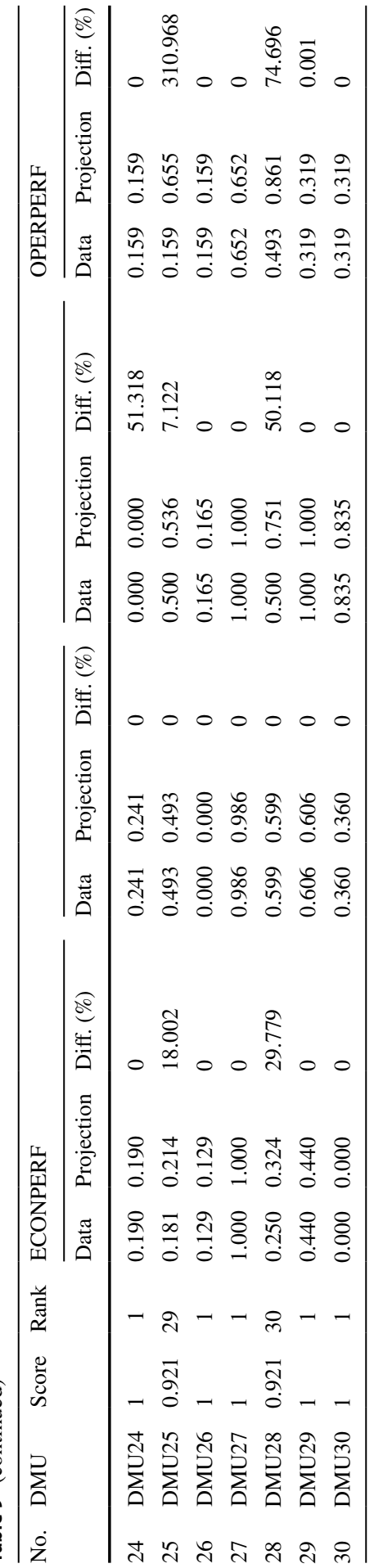




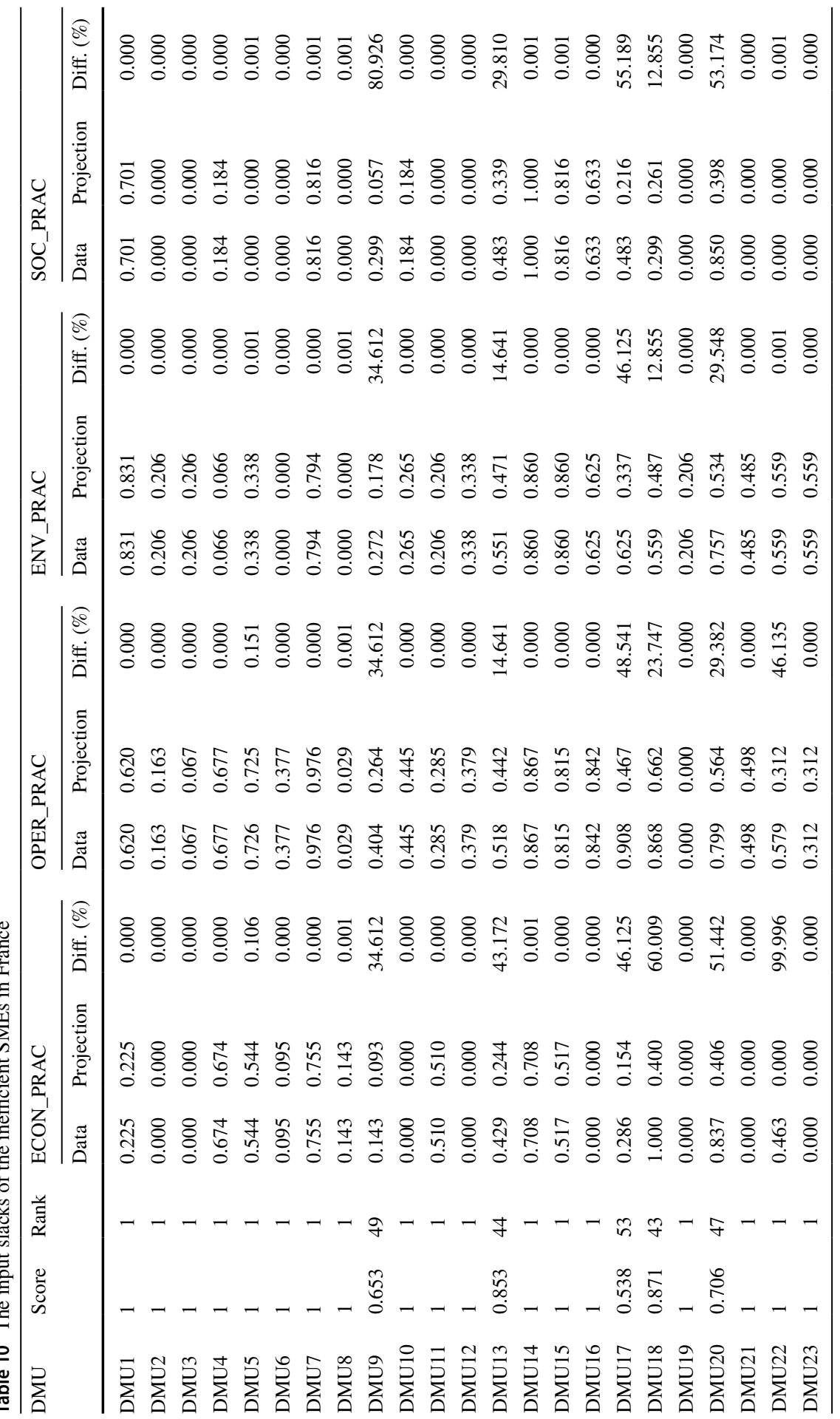




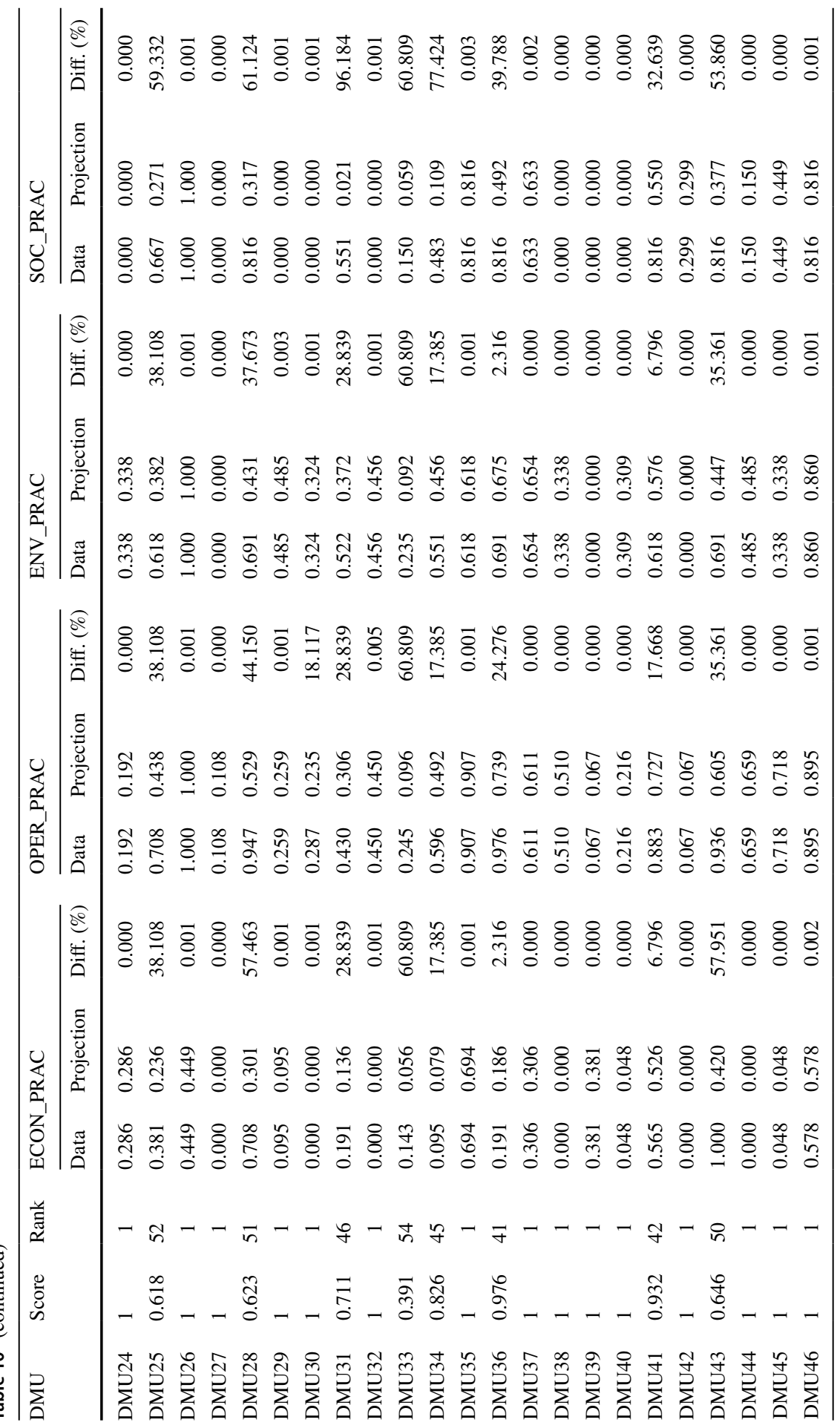




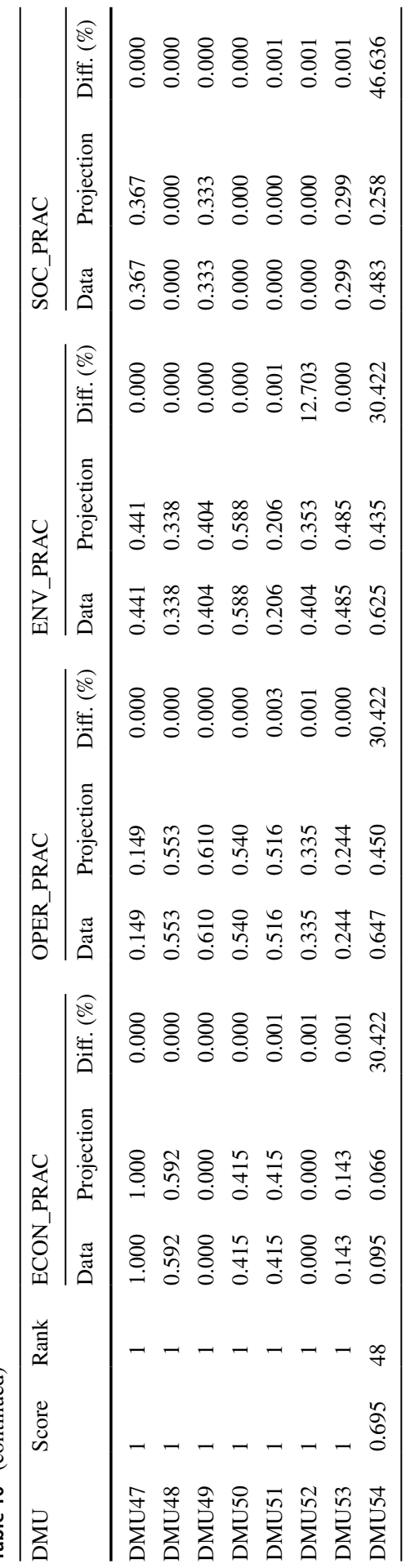




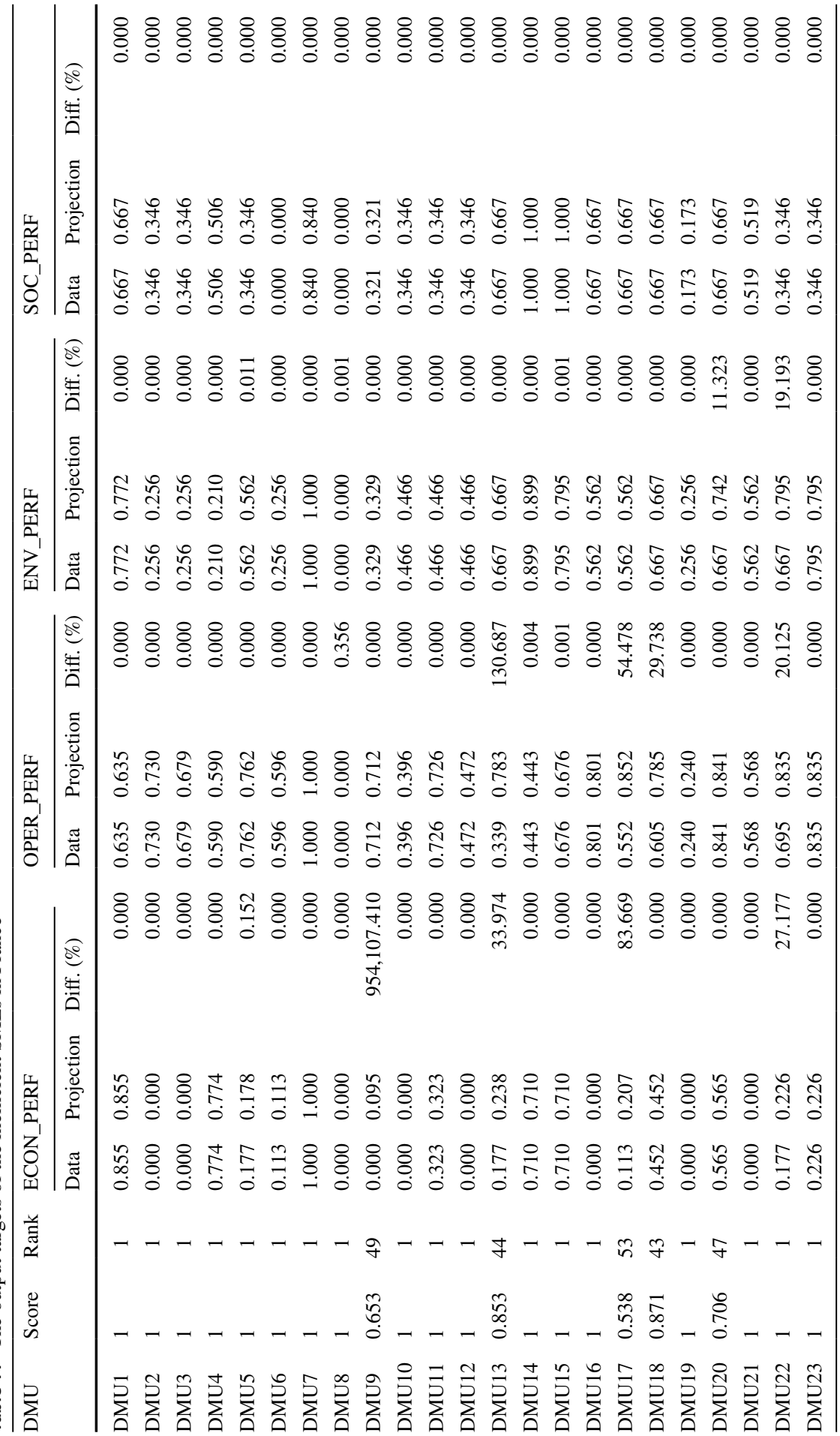




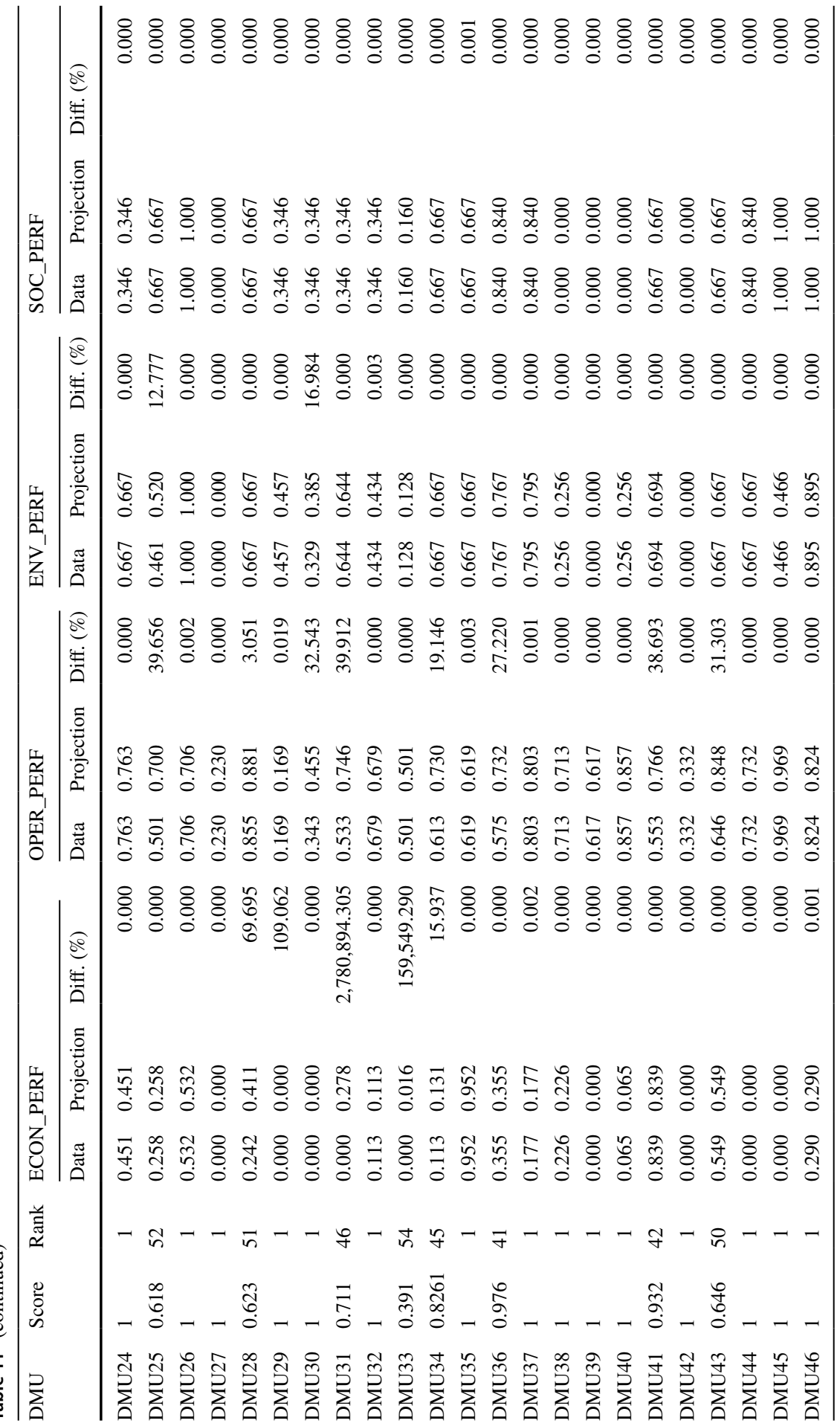




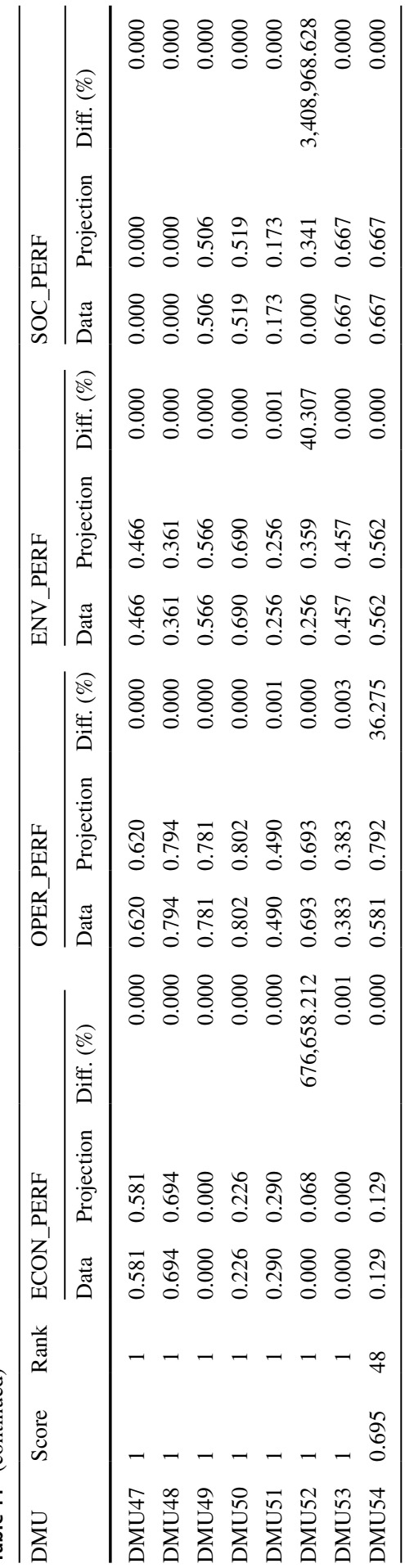




\section{References}

Abdul-Rashid, S. H., Sakundarini, N., Raja Ghazilla, R. A., \& Thurasamy, R. (2017). The impact of sustainable manufacturing practices on sustainability performance: Empirical evidence from Malaysia. International Journal of Operations \& Production Management, 37(2), 182-204.

Acquaye, A., Feng, K., Oppon, E., Salhi, S., Ibn-Mohammed, T., Genovese, A., et al. (2017). Measuring the environmental sustainability performance of global supply chains: A multi-regional input-output analysis for carbon, sulphur oxide and water footprints. Journal of Environmental Management, 187, 571-585.

Ali, A. I., \& Seiford, L. M. (1990). Translation invariance in data envelopment analysis. Operations Research Letters, 9, 403-405.

Arbuckle, J. L. (2014). Amos 23.0 user's guide. Chicago: IBM SPSS.

Ates, A., Garengo, P., Cocca, P., \& Bititci, U. (2013). The development of SME managerial practice for effective performance management. Journal of Small Business and Enterprise Development, 20(1), 28-54.

Azadia, M., Jafarianb, M., Saen, R. F., \& Mirhedayatian, S. M. (2015). A new fuzzy DEA model for evaluation of efficiency and effectiveness of suppliers in sustainable supply chain management context. Computer and Operations Research, 54, 274-285.

Banker, R. D. (1993). Maximum likelihood, consistency and data envelopment analysis: A statistical foundation. Management Science, 39(10), 1265-1273.

Banker, R. D., Charnes, A., \& Cooper, W. W. (1984). Some models for estimating technical and scale inefficiencies in data envelopment analysis. Management Science, 30(9), 1078-1092.

Bhagwat, R., \& Sharma, M. K. (2007). Performance measurement of supply chain management: A balanced scorecard approach. Computers \& Industrial Engineering, 53(1), 43-62.

Bhattacharya, A., Mohapatra, P., Kumar, V., Dey, P. K., Brady, M., Tiwari, M. K., et al. (2013). Green supply chain performance measurement using fuzzy ANP-based balanced scorecard: a collaborative decision-making approach. Production Planning \& Control: SI - The Management of Operations. https://doi.org/10.1080/09537287.2013.798088.

Bititci, U., Garengo, P., Dörfler, V., \& Nudurupati, S. (2012). Performance measurement: Challenges for tomorrow. International Journal of Management Reviews, 14(3), 305.

Bjorklund, M., Martinsen, U., \& Abrahamsson, M. (2012). Performance measurements in the greening of supply chains. Supply Chain Management: An International Journal, 17(1), 29-39.

Bollen, K. A. (1989). Structural equations with latent variables. New York: Wiley-Interscience.

Büyüközkan, G., \& Karabulut, Y. (2018). Sustainability performance evaluation: Literature review and future directions. Journal of Environmental Management, 217, 253-267.

Cao, J., Chen, G., Khoveyni, M., Eslami, R., \& Yang, G. (2016). Specification of a performance indicator using the evidential-reasoning approach. Knowledge-Based Systems, 92, 138-150.

Chan, F. T. S., \& Qi, H. J. (2003). An innovative performance measurement method for supply chain management. Supply Chain Management: An International Journal, 8(3), 209-223.

Charnes, A., Cooper, W. W., \& Rhodes, E. (1978). Measuring the efficiency of decision making units. European Journal of Operational Research, 2(6), 429-444.

Chay, T., Xu, Y., Tiwari, A., \& Chay, F. (2015). Towards lean transformation: The analysis of lean implementation frameworks. Journal of Manufacturing Technology Management, 26(7), 1031-1052.

Devins, D., Johnson, S., \& Sutherland, J. (2004). Employer characteristics and employee training outcomes in UK SMEs: A multivariate analysis. Journal of Small Business and Enterprise Development, Bradford, 11(4), 449-457.

Dey, P. K., \& Cheffi, W. (2012). Green supply chain performance measurement using the analytic hierarchy process: A comparative analysis of manufacturing organisations. Production Planning and Control: The Management of Operations, 24(8-9), 702-720.

Dey, P. K., \& Cheffi, W. (2013). Managing supply chain integration: Contemporary approaches and scope for further research. Production Planning and Control: The Management of Operations, 24(8-9), 653-657.

Dey, P. K., Malesios, C., De, D., Chowdhury, S., \& Abdelaziz, F. B. (2018). Could lean practices and process innovation enhance supply chain sustainability of small and medium sized enterprises? Business Strategy and the Environment. https://doi.org/10.1002/bse.2266. 
Fen Tseng, Y., Jim Wu, Y., Wu, W., \& Chen, C. (2010). Exploring corporate social responsibility education. Management Decision, 48(10), 1514-1528.

Fitzgerald, L., Johnson, R., Brignall, S., Silvestro, R., \& Voss, C. (1991). Performance measurement in service businesses. London: CIMA.

Garengo, P., Biazzo, S., \& Bititci, U. S. (2005). Performance measurement systems in SMEs: A review for a research agenda. International Journal of Management Reviews, 7(1), 25-47.

Gavronski, I., Klassen, R. D., Vachon, S., \& do Nascimento, L. F. M. (2011). A resource-based view of green supply management. Transportation Research Part E: Logistics and Transportation Review, 47(6), 872-885.

Groves, C., Frater, L., Lee, R., \& Stokes., H. (2011). Is there room at the bottom for CSR? Corporate social responsibility and nanotechnology in the UK. Journal of Business Ethics, 101(4), 525-552.

Gunasekaran, A., Parel, C., \& Mc Gaughey, R. E. (2004). A framework for supply chain performance measurement. International Journal of Production Economics, 87(3), 333-347.

Halkos, G. E., \& Evangelinos, K. (2002). Determinants of environmental management systems standards implementation: Evidence from Greek industry. Business Strategy and the Environment, 11(6), 360-375.

Halkos, G. E., \& Polemis, G. (2018). The impact of economic growth on environmental efficiency of the electricity sector: A hybrid window DEA methodology for the USA. Journal of Environmental Management, 211, 334-346.

Halkos, G. E., Tzeremes, N. G., \& Kourtzidis, S. A. (2015a). Regional sustainability efficiency index in Europe: An additive two-stage DEA approach. Operational Research, 15(1), 1-23.

Halkos, G. E., Tzeremes, N. G., \& Kourtzidis, S. A. (2015b). Measuring sustainability efficiency using a two-stage data envelopment analysis approach. Journal of Industrial Ecology, 20(5), 1159-1175.

Hall, J. (2000). Environmental supply chain dynamics. Journal of Cleaner Production, 8, 455-471.

Hanim, H., Bakri, M., Mohamed, N., \& Said, J. (2017). Mitigating asset misappropriation through integrity and fraud risk elements: evidence emerging economies. Journal of Financial Crime, 24(2).

Hassini, E., Surti, C., \& Searcy, C. (2012). A literature review and a case study of sustainable supply chains with a focus on metrics. International Journal of Production Economics, 140(1), 69-82.

Hoejmose, S., Brammer, S., \& Millington, A. (2013). An empirical examination of the relationship between business strategy and socially responsible supply chain management. International Journal of Operations \& Production Management, 33(5), 589-621.

Hu, Q., Mason, R., Williams, S. J., \& Found, P. (2015). Lean implementation within SMEs: A literature review. Journal of Manufacturing Technology Management, 26(7), 980-1012.

Jamali, D., Zanhour, M., \& Keshishian, T. (2009). Peculiar strengths and relational attributes of SMEs in the context of CSR. Journal of Business Ethics, 87, 355-367.

Johnson, M. P. (2015). Sustainability management and small and medium-sized enterprises: Managers awareness and implementation of innovative tools. Corporate Social Responsibility and Environmental Management, 22(5), 281-285.

Johnson, M. P., \& Schaltegger, S. (2016). Two decades of sustainability management tools for SMEs: How far have we come? Journal of Small Business Management, 54(2), 481-505.

Jöreskog, K. G. (1994). Structural equation modeling with ordinal variables. Multivariate analysis and its applications (pp. 297-310). Hayward, CA: Institute of Mathematical Statistics.

Kainuma, Y., \& Tawara, N. (2006). A multiple attribute utility theory approach to lean and green supply chain management. International Journal of Production Economics, 101, 99-108.

Kaplan, R. S., \& Norton, D. (1996). Using the balanced scorecard as a strategic management system. Harvard Business Review, 74(1), 75-85.

Kim, J., Realff, M. J., \& Lee, J. H. (2011). Optimal design and global sensitivity analysis of biomass supply chain networks for biofuels under uncertainty. Computers \& Chemical Engineering, 35(9), 1738-1751.

Kleindorfer, P.-R., Singhal, K., \& Wassenhove, L.-N.-V. (2005). Sustainable operations management. Production and Operations Management, 14(4), 482-492.

Kneip, A., Simar, L., \& Wilson, P. W. (2008). Asymptotics and consistent bootstraps for DEA estimators in non-parametric frontier models. Econometric Theory, 24, 1663-1697.

Koh, S. C. L., \& Simpson, M. (2005). Change and uncertainty in SME manufacturing environments using ERP. Journal of Manufacturing Technology Management, 16(5/6), 629-653.

Korostelev, A., Simar, L., \& Tsybakov, A. B. (1995). On estimation of monotone and convex boundaries. Publicaitons de l'Institut de Statistique de l'Universit'e de Paris XXXIX 1, 3-18. 
Lee, S. Y., \& Klassen, R. D. (2008). Drivers and enablers that foster environmental management capabilities in small- and medium-sized suppliers in supply chains. Production and Operations Management, 17(6), 573-586.

Lewis, W. G., Pun, K. F., \& Lalla, T. R. M. (2006). Empirical investigation of the hard and soft criteria of TQM in ISO 9001 certified small and medium-sized enterprises. The International Journal of Quality \& Reliability Management, 23(8), 964-985.

Lynch, R., \& Cross, K. (1991). Measure up! Yardsticks for continuous improvement. Cambridge: Blackwell.

Malesios, C., Dey, P. K., \& Abdelaziz, F. B. (2018). Supply chain sustainability performance measurement of small and medium sized enterprises using structural equation modeling. Annals of Operations Research. https://doi.org/10.1007/s10479-018-3080-z.

Marr, B., \& Creelman, J. (2011). More with less: Maximizing value in the public sector. Basingstoke: Palgrave Macmilllan.

Mollenkopf, D. (2008). Drivers and barriers to environmental supply chain management practices: Lessons from the public and private sectors. Journal of Purchasing and Supply Management, 14, 69-85.

Neely, A., Adams, C., \& Kennerley, M. (2002). The performance prism: The scorecard for measuring and managing stakeholder relationship. London: Prentice Hall.

Neely, A., Gregory, M., \& Platts, K. (1995). Performance measurement system design: A literature review and research agenda. International Journal of Operations \& Production Management, 15(4), $80-116$.

Nguyen, T. H., \& Waring, T. S. (2013). The adoption of customer relationship management (CRM) technology in SMEs: An empirical study. Journal of Small Business and Enterprise Development, 20(4), 824-848.

Nudurupati, S. S., Bititci, U. S., Kumar, V., \& Chan, F. T. S. (2011). State of the art literature review on performance measurement. Computers \& Industrial Engineering, 60(2), 279-290.

Orsato, R.-J. (2006). Competitive Environmental strategies: When does it pay to be green? California Management Review, 48(2), 127-143.

Pala, M., Edum-Fotwe, F., Ruikar, K., Doughty, N., \& Peters, C. (2014). Contractor practices for managing extended supply chain tiers. Supply Chain Management, 19(1), 31-45.

Patyal, V. S., \& Koilakuntla, M. (2015). Infrastructure and core quality practices in Indian manufacturing organizations: Scale development and validation. Journal of Advances in Management Research, Bingley, 12(2), 141-175.

Poister, T. H. (2003). Measuring performance in public and nonprofit organizations. San Francisco, CA: Jossey-Bass.

Quah, H. S., \& Udin, Z. M. (2011). Supply chain management from the perspective of value chain flexibility: An exploratory study. Journal of Manufacturing Technology Management, 22(4), 506-526.

Ramezankhani, M. J., Ali Torabi, S., \& Vahidi, F. (2018). Supply chain performance measurement and evaluation: A mixed sustainability and resilience approach. Computers \& Industrial Engineering, 126, 531-548.

Santos, M. (2011). CSR in SMEs: strategies, practices, motivations and obstacles. Social Responsibility Journal, 7(3), 490-508.

Seuring, S., \& Muller, M. (2008). From a literature review to a conceptual framework for sustainable supply chain management. Journal of Cleaner Production, 16, 1699-1710.

Sharma, M. K., Bhagwat, R., \& Dangayach, G. S. (2005). Practice of performance measurement: Experience from Indian SMEs. International Journal of Globalisation and Small Business, 1(2), 183-213.

Shen, W., Zhang, D., Liu, W., \& Yang, G. (2016). Increasing discrimination of DEA evaluation by utilizing distances to anti-efficient frontiers. Computers \& Operations Research, 75, 163-173.

Shepherd, C., \& Gunter, H. (2005). Measuring supply chain performance: Current research and future directions. International Journal of Productivity and Performance Management, 55(3-4), 242-258.

Shi, Q., Zuo, J., \& Zillante, G. (2012). Exploring the management of sustainable construction at the programme level-A Chinese case study. Construction Management and Economics, 30(6), 425-440.

Smith, P. (1997). Model misspecification in data envelopment analysis. Annals of Operations Research, 73, 233-252.

Sullivan-Taylor, B., \& Branicki, L. (2011). Creating resilient SMEs: Why one size might not fit all. International Journal of Production Research, 49(18), 5565-5579.

$\mathrm{Su}-Y o l$, L. (2008). Drivers for the participation of small and medium-sized suppliers in green supply chain initiatives. Supply Chain Management, 13(3), 185-198. 
Taticchi, P., Cagnazzo, L., \& Tonelli, F. (2010). Performance measurement and management: A literature review and a research agenda. Measuring Business Excellence, 14(1), 4-18.

Taticchi, P., Tonelli, F., \& Cagnazzo, L. (2009). A decomposition and hierarchical approach for business performance measurement and management. Measuring Business Excellence, 13(4), 47-57.

Taticchi, P., Tonelli, F., \& Pasqualino, R. (2013). Performance measurement of sustainable supply chains. A literature review and a research agenda. International Journal of Productivity and Performance Management, 62(8), 782-804.

Thanassoulis, E., Dey, P. K., Petridis, K., Goniadis, I., \& Georgiou, A. C. (2017). Evaluating higher education teaching performance using combined analytic hierarchy process and data envelopment analysis. Journal of the Operational Research Society, 68, 431-554.

Thomas, D. J., \& Griffin, P. M. (1996). Co-ordinated supply chain management. European Journal of Operational Research, 94(3), 1-15.

Towers, N., \& Burnes, B. (2008). A composite framework of supply chain management and enterprise planning for small and medium-sized manufacturing enterprises. Supply Chain Management, 13(5), $349-355$.

Vidal, J. (2013). UK government failing legal duty on air pollution. Supreme Court rules, Environment, guardian.co.uk, Guardian.

Walker, H., \& Jones, N. (2012). Sustainable supply chain management across the UK private sector. Supply Chain Management, 17(1), 15-28.

West, J. (2014). Challenges of funding open innovation platforms: Lessons from Symbian Ltd. In H. Chesbrough, W. Vanhaverbeke, J. West (Eds.), New Frontiers in Open Innovation (pp.29-49). Oxford: Oxford University Press.

Whyman, P. B., \& Petrescu, A. I. (2015). Workplace flexibility practices in SMEs: Relationship with performance via redundancies, absenteeism, and financial turnover. Journal of Small Business Management, 53(4), 1097.

Wolff, J. A., \& Pett, T. L. (2006). Small-firm performance: Modeling the role of product and process improvements. Journal of Small Business Management, 44(2), 268-284.

Wong, W. P., \& Wong, K. Y. (2007). Supply chain performance measurement system using DEA modelling. Industrial management \& Data system, 107(3), 361-381.

Wyld, J., Pugh, G., \& Tyrrall, D. (2012). Can powerful buyers “exploit” SME suppliers? Journal of Small Business and Enterprise Development, 19(2), 322-334.

Zhu, Q., \& Sarkis, J. (2004). Relationships between operational practices and performance among early adopters of green supply chain management practices in Chinese manufacturing enterprises. Journal of Operations Management, 22, 265-289.

Zhu, Q., Sarkis, J., \& Lai, K.-H. (2007a). Green supply chain management: Pressures, practices and performance within the Chinese automobile industry. Journal of Cleaner Production, 15(11-12), 1041-1052.

Zhu, Q., Sarkis, J., \& Lai, K.-H. (2007b). Initiatives and outcomes of green supply chain management implementation by Chinese manufacturers. Journal of Environmental Management, 85(1), 179-189.

Publisher's Note Springer Nature remains neutral with regard to jurisdictional claims in published maps and institutional affiliations. 


\section{Affiliations}

\section{Prasanta Kumar Dey ${ }^{1} \cdot$ Guo-liang Yang ${ }^{2} \cdot$ Chrysovalantis Malesios $^{1}$ (1) . Debashree $\mathrm{De}^{1} \cdot$ Konstantinos Evangelinos $^{3}$}

$\triangle$ Chrysovalantis Malesios

c.malesios@aston.ac.uk

Prasanta Kumar Dey

p.k.dey@aston.ac.uk

Guo-liang Yang

glyang@casipm.ac.cn

Debashree De

ded1@aston.ac.uk

Konstantinos Evangelinos

kevag@aegean.gr

1 Aston Business School, Aston University, Birmingham B4 7ET, UK

2 Institutes of Science and Development, Chinese Academy of Sciences, Beijing 100190, China

3 Department of Environment, University of the Aegean, 81100 Mytilene, Greece 